\title{
Multiple Anti-Kasha Emissions in Transition Metal Complexes
}

Milena Röhrs, Daniel Escudero

Submitted date: 11/07/2019 Posted date: 11/07/2019

Licence: CC BY-NC-ND 4.0

Citation information: Röhrs, Milena; Escudero, Daniel (2019): Multiple Anti-Kasha Emissions in Transition Metal Complexes. ChemRxiv. Preprint.

In this manuscript we present a from-first-principlesevidence that several higher-lying excited states are responsible for the emission spectrum of $\left[\mathrm{M}(\mathrm{CO})_{4}(\mathrm{bpy})\right](\mathrm{M}=\mathrm{Cr}$, Mo, W and bpy=2,2'-bipyrimidine) complexes. These results highlight the violation of Kasha's rule, which states that after irradiation molecules emit light with appreciable yield only from its lowest energy excited state. Furthermore, in $\left[\mathrm{W}(\mathrm{CO})_{4}(\mathrm{bpy})\right]$ and $\left[\mathrm{Mo}(\mathrm{CO})_{4}(\mathrm{bpy})\right]$, the breaking of Kasha's rule is two-fold, because at least two different excited states besides $\mathrm{T}_{1}$ are involved in emission. To our knowledge, these are the first transition metal complexes unambiguously demonstrated to display simultaneous equilibrated and non-equilibrated anti-Kasha emissions. This work also highlights the complexity of the emissive processes of tetracarbonyl-diimine transition metal complexes, which are controlledviaa subtle interplay of electronic and geometrical effects along the excited state deactivation dynamics.

File list (2)

Escudero_Chemrxiv.pdf (0.96 MiB)

view on ChemRxiv - download file

SI_Escudero.pdf (1.29 MiB)

view on ChemRxiv - download file 


\title{
Multiple Anti-Kasha emissions in transition metal complexes
}

\author{
Milena Röhrs, ${ }^{[\mathrm{a}]}$ and Daniel Escudero* ${ }^{[\mathrm{a}]}$
}

\begin{abstract}
In this manuscript we present a from-first-principles evidence that several higher-lying excited states are responsible for the emission spectrum of $\left[\mathrm{M}(\mathrm{CO})_{4}(\mathrm{bpy})\right](\mathrm{M}=\mathrm{Cr}$, Mo, $\mathrm{W}$ and bpy=2,2'-bipyrimidine) complexes. These results highlight the violation of Kasha's rule, which states that after irradiation molecules emit light with appreciable yield only from its lowest energy excited state. Furthermore, in $\left[\mathrm{W}(\mathrm{CO})_{4}(\mathrm{bpy})\right]$ and $\left[\mathrm{Mo}(\mathrm{CO})_{4}(\mathrm{bpy})\right]$, the breaking of Kasha's rule is two-fold, because at least two different excited states besides $T_{1}$ are involved in emission. To our knowledge, these are the first transition metal complexes unambiguously demonstrated to display simultaneous equilibrated and nonequilibrated anti-Kasha emissions. This work also highlights the complexity of the emissive processes of tetracarbonyldiimine transition metal complexes, which are controlled via a subtle interplay of electronic and geometrical effects along the excited state deactivation dynamics.
\end{abstract}

\section{Introduction}

Observation of believed scientific rules being broken leads often to new knowledge and promisingly to important applications. Kasha rule states that "the emitting electronic level of a given multiplicity is the lowest excited level of that multiplicity". ${ }^{1}$ The initial formulation of Kasha's rule was later extended to include not only emission processes but also excited state reactivity, that is "polyatomic molecular entities react with appreciable yield only from the lowest excited state of a given multiplicity". ${ }^{2}$ According to Itoh, ${ }^{3}$ anti-Kasha events can be classified into thermally or non-thermally equilibrated cases. In general, as kinetic control is always at play in photochemistry, most of the molecular systems behave in a Kasha-like manner. This is because higher-lying excited states (ES) are extremely short-lived, due to the ultrafast relaxation by internal conversion (IC) to the lowest ES; and thus, photoreactions and/or photoluminescence from the higher-lying ES (i.e., non-thermally equilibrated case) are generally not fast enough to compete with IC; but also because the possibility of having close-lying ESs (within the $k_{B} T$ energy window) near the lowest ES is unlikely (i.e., thermally equilibrated case). While examples of molecular systems breaking Kasha rule are known since the late 50's, such as e.g., azulene, ${ }^{4,5}$ those examples were believed to be a few exceptions. This was so because these "hot" photochemical reactions were difficult to track experimentally, but also because low-lying dark excited states are silent to many spectroscopic techniques. In steady-state photoluminescence experiments, the presence of a single emission band does not guarantee per se its occurrence from the lowest-lying ES. Thus, the observance or violation of Kasha rule needs further experimental evidences. For instance, excitation wavelength- and/or temperature-dependent emissive features are characteristic footprints for anti-Kasha photoluminescence. Sometimes, a simple inspection of the steady-state emission spectrum can hint to violations of Kasha rule, as e.g., when dual (or multiple) emissions are observed. However, photoreactions might also lead to dual emissions scenarios. ${ }^{6}$ The latter cases are strictly not violating Kasha rule because different chemical species (i.e., products and reactants) are responsible for the different emissive bands.

In recent years, with the progresses in both experimental and computational techniques to unambiguously track ES species and their photodeactivation dynamics, more molecular systems have been proven to violate Kasha rule. $^{7}$ There is still some controversy in some of the systems claimed to behave in an anti-Kasha manner. For instance Catalán and coworkers recently claimed that Kasha rule still holds true for the majority of the investigated organic compounds. ${ }^{8}$ Conversely, transition metal complexes (TMCs), due to their higher density of excited states of different spin and character, often display more complex and chameleonic photochemical properties than those of organic compounds. ${ }^{9}$ Their ES photodeactivation dynamics are also more intricate, since intersystem crossing (ISC) often occur in the ultrafast regime (i.e., from few femtoseconds to the picosecond regime) and thus, ISC directly competes with IC. Hence, TMCs can undergo a plethora of interconnected ES deactivation processes, which compete to each other, and which are controlled by geometrical and electronic factors. Intrinsic factors such as the character and spin of the involved ESs along with their effective couplings and their

[a] Milena Röhrs, Prof. Daniel Escudero Department of Chemistry. Quantum Chemistry and Physical Chemistry Division.

KU Leuven

Celestijnenlaan 200F, B-3001 Heverlee, Belgium

E-mail: Daniel.escudero@kuleuven.be energetic alignment determine the preferred ES deactivation channels and/or the branching of the ES population. Furthermore, the situation of having multiple close-lying ES is not rare for TMCs, and the combination of all these characteristics leads the document. 
at different timescales. To showcase this complexity, dual emissive scenarios have been reported for TMCs, including $\mathrm{Ag}(\mathrm{I}),{ }^{10} \mathrm{Ir}(\mathrm{III}),{ }^{11,12,13} \mathrm{Pt}(\mathrm{II}),{ }^{14,15} \mathrm{Rh}(\mathrm{I}),{ }^{16} \mathrm{Os}(\mathrm{II}){ }^{17}$ and $\mathrm{Ru}(\mathrm{II}) .{ }^{18,19}$ Both dual singlet-triplet and triplet-triplet scenarios have been reported.

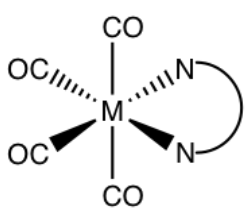<smiles>c1ccc(-c2ccccn2)nc1</smiles>

bpy<smiles>c1cnc2c(c1)ccc1cccnc12</smiles>

phen<smiles>Cc1cnc2c(ccc3c(C)c(C)cnc32)c1C</smiles>

tmp

Scheme 1. $M(C O)_{4} L(M=C r, M o, W ; L=b p y$, phen, tmp) complexes.

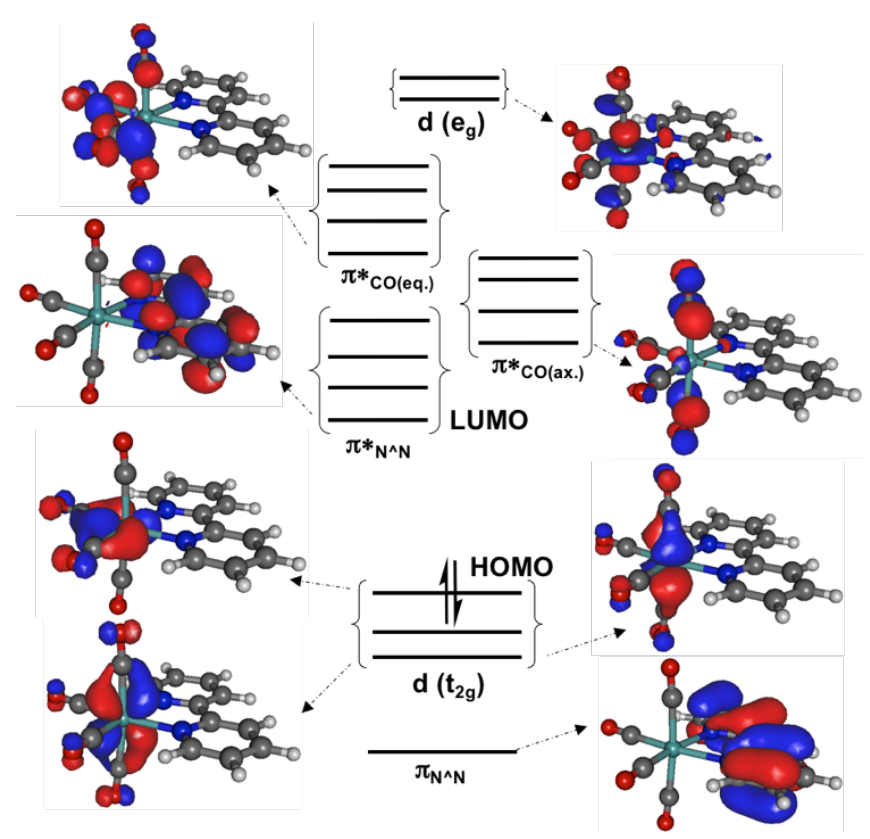

Scheme 2. Qualititative molecular orbital diagram for $M(C O)_{4} L$ complexes.

The electrochemical, photophysical and photochemical properties of group 6 complexes of the type $M(C O)_{4} L$ (where $\mathrm{M}=\mathrm{Cr}$, Mo, $\mathrm{W}$; and $\mathrm{L}$ is a $\alpha$-diimine ligand, such as e.g., 2,2'-bipyrimidine(bpy) or 1,10'-phenantroline (phen)), see Scheme 1, were examined with experimental techniques. ${ }^{20},{ }^{21}$ In terms of applications, these complexes have recently emerged as efficient electrocatalysts for $\mathrm{CO}_{2}$ reduction, especially in the case of the Mo and $\mathrm{W}$ complexes. ${ }^{22}{ }^{23}$ Thus, due to their rich physical and chemical aspects but also due to their relative molecular simplicity, these complexes are excellent model systems to test novel experimental and theoretical approaches. The group 6 complexes of the type $\mathrm{M}(\mathrm{CO})_{4} \mathrm{~L}$ possess many common electronic features. ${ }^{24}$ In Scheme 2 is shown a qualitative molecular orbital (MO) diagram, which includes the most relevant orbitals involved in their photochemistry. The three highest occupied MOs (HOMOs) are located in an energetically narrow range and mainly correspond to the set of $t_{2 g}$ metal $d$ orbitals, while HOMO-4 is a $\pi_{\mathrm{N}^{\wedge} \mathrm{N}}$ orbital. The lowest unoccupied MOs (LUMOs) of $\mathrm{M}(\mathrm{CO})_{4} \mathrm{~L}$ complexes correspond to $\pi^{*} \mathrm{~N}^{\wedge} \mathrm{N}$ orbitals, see for instance LUMO in Scheme 2. Higher in energy appear in increasing energetic order the set of $\pi * \mathrm{co}_{(\mathrm{ax} .)}$ and $\pi * \mathrm{co}_{\text {(eq.) }}$ MOs. Finally, much higher in energy appear the set of $e_{g}$ metal $d$ orbitals. The diversity of MOs in a narrow energy range leads to a manifold of closelying ES of different character, i.e., from metal-to-ligand charge transfer (MLCT) involving both CO and L ligands as well as ligand-centered (LC) or metal-centered (MC) ESs. Experimentally, in terms of photoreactivity, these complexes undergo excitation wavelength-dependent photochemical substitution of an axial CO ligand, ${ }^{24}$ being the yields of this reaction strongly dependent on the nature of $i$ ) the central atom and ii) the $L$ ligand, but also on 
other extrinsic effects, such as temperature, pressure and environmental conditions (solvent). Concerning their emission properties, they generally exhibit multiple photoluminescence features in room temperature solutions and in low-temperature glasses, leading to two emission bands separated by ca. $4000 \mathrm{~cm}^{-1}$, and which are identified as high-energy (HE) and low-energy (LE) bands. ${ }^{20,24}$ All emitting states responsible of these bands possess considerable triple character. ${ }^{24}$ For some of the complexes, e.g., $\mathrm{W}(\mathrm{CO})_{4}(\mathrm{phen})$ and $\mathrm{W}(\mathrm{CO})_{4}(\mathrm{tmp})(\operatorname{tmp}=3,4,7,8-$ tetramethyl-1,10'-phenantroline), time-resolved emission spectra were recorded ${ }^{25}$ For these complexes, the HE emission is very short-lived ( $<36 \mathrm{~ns}$ ), and it is excitation wavelength-dependent, since it fully develops only upon UV excitation. It likely originates in several radiative transitions for these complexes. ${ }^{25}$ The LE band is thermallyequilibrated, it displays biexponential photoluminescence decay and it is longer-lived than the HE band (i.e., the measured lifetimes for $\mathrm{W}(\mathrm{CO})_{4}$ (phen) are 150 and $487 \mathrm{~ns}$ ). In addition, the time-resolved experiments highlighted that the emitting states responsible for the HE and LE bands are not in thermal equilibrium, regardless of the temperature. ${ }^{25}$ The assignment of the ES responsible of the LE and HE bands is more controversial. Early stage investigations ${ }^{20}$ pointed to several triplet ${ }^{3} \mathrm{MLCT}$ states involving the $\mathrm{N}^{\wedge} \mathrm{N}$ ligand $\left({ }^{3} \mathrm{MLCT}_{\mathrm{N}^{\wedge} \mathrm{N}}\right)$ to be responsible of the LE band while ${ }^{3} \mathrm{MC}$ state(s) being responsible for the HE band. Later investigations, ${ }^{25}$ which also included timedependent density functional theory (TD-DFT) calculations at the Franck-Condon region, concluded that the lowest-lying ${ }^{3} \mathrm{MLCT}_{\mathrm{N}^{\wedge} \mathrm{N}}$ states are likely responsible for the LE band, but conversely the HE band likely originates from ${ }^{3} \mathrm{MLCT}$ states involving the $\mathrm{CO}$ ligands $\left({ }^{3} \mathrm{MLCT}_{\mathrm{CO}}\right)$. In this contribution we aim at shedding some light into this controversy by identifying the ES unambiguously involved in the emission process and by rationalizing the origins of the anti-Kasha behavior in these complexes. Towards this end, high-level ab initio coupled-cluster and TD-DFT calculations are performed.

\section{Results and Discussion}

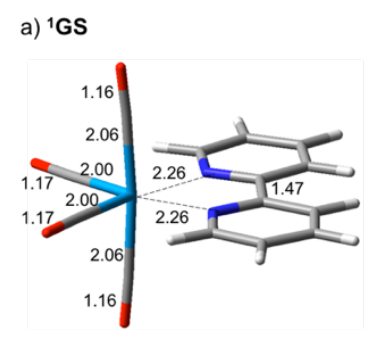

e) ${ }^{3} \mathrm{MC}$

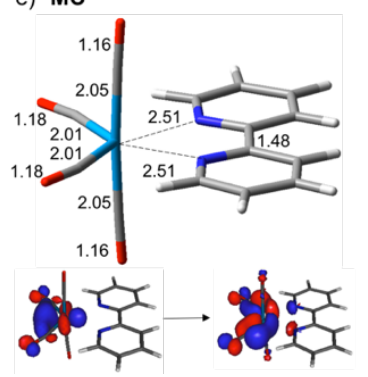

b) ${ }^{3} \mathrm{MLCT}_{\mathrm{bpy}}(1)$

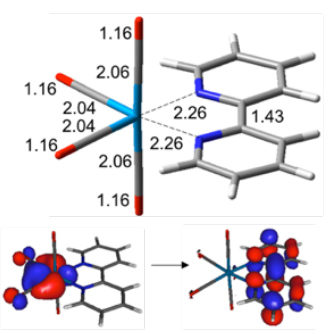

f) ${ }^{3} \mathrm{LC}$

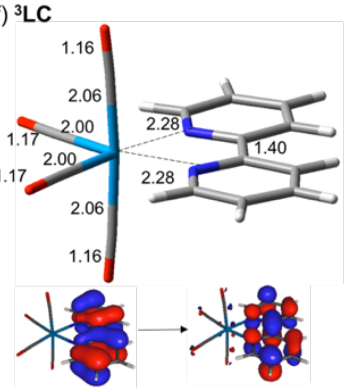

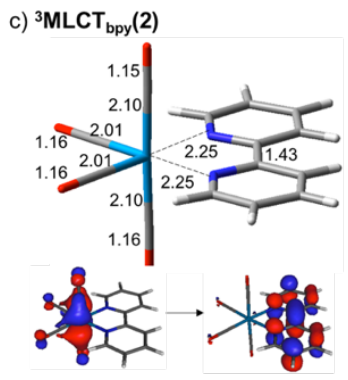

g) ${ }^{3} \mathrm{MLCT}_{\mathrm{CO}}$

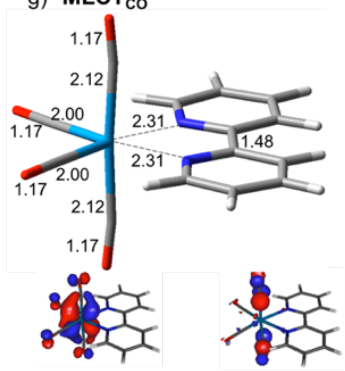

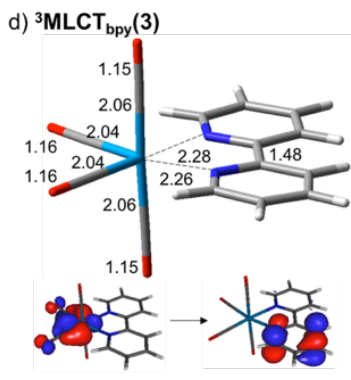

h) ${ }^{3} \mathrm{MLCT}_{\text {bpy }}(4)$

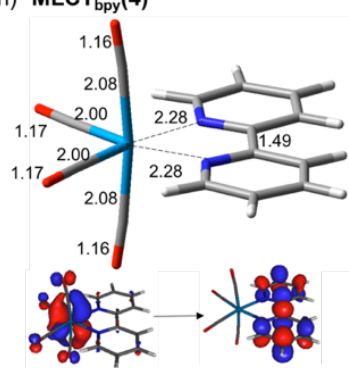

Figure 1. Main geometrical features of the optimized structures of ${ }^{1} \mathrm{GS},{ }^{3} \mathrm{MLCT}_{\mathrm{bpy}}(1),{ }^{3} \mathrm{MLCT}_{\mathrm{bpy}}(2),{ }^{3} \mathrm{MLCT} \mathrm{bpy}_{\mathrm{b}}(3),{ }^{3} \mathrm{MC},{ }^{3} \mathrm{LC}^{3}{ }^{3} \mathrm{MLCT} \mathrm{Co}$ and ${ }^{3} \mathrm{MLCT}_{\text {bpy }}(4)$ for $\mathrm{W}(\mathrm{CO})_{4}(\mathrm{bpy})$. Below each optimized structure are shown the orbitals involved in their corresponding TD-DFT electronic transitions. Bond distances are given in $\AA$.

Table 1. Emission Maxima for $\mathrm{M}(\mathrm{CO})_{4}(\mathrm{bpy})$ Complexes in Benzene at $298 \mathrm{~K}^{\mathrm{a}}$

\begin{tabular}{lcc}
\hline & HE band & LE band \\
\hline $\mathbf{W}(\mathbf{C O})_{4}($ bpy $)$ & 17030 & 12970 \\
$\mathbf{M o}(\mathbf{C O})_{4}$ (bpy) & 17300 & 12940 \\
\hline
\end{tabular}

[a] From ref. 20

Owing to the common photophysical properties of group $6 \mathrm{M}(\mathrm{CO})_{4} \mathrm{~L}$ complexes, we herein focus our computational efforts on the following bpy derivatives: $\mathrm{W}(\mathrm{CO})_{4}(\mathrm{bpy})$ and $\mathrm{Mo}(\mathrm{CO})_{4}(\mathrm{bpy})$. As discussed above, the photophysical properties of these complexes were investigated experimentally (see in Table 1 their emission data) and with TD- 
DFT, ${ }^{25}$ but these studies were restricted at the Franck-Condon region. bands Herein, we go beyond in complexity by exploring the triplet ES potential energy surface (PES), so that important geometric relaxation effects along the ES photodeactivation dynamics can be captured. Due to the presence of a high density of close-lying ESs of different character, many of those ESs might be responsible for the measured emission bands. Therefore, we performed TD-DFT optimizations of the first twenty-five triplet excited states to locate ES minima (see computational details in the experimental section). With this brute force protocol to explore the triplet ES PESs we were able to optimize the geometries of seven different triplet excited states for both $\mathrm{Mo}(\mathrm{CO})_{4}(\mathrm{bpy})$ and $\mathrm{W}(\mathrm{CO})_{4}(\mathrm{bpy})$. The other trials were either unsuccessful or ended up in the wells of those seven ES minima. The optimized geometries of the seven triplet excited state minima and of the ground state $\left({ }^{1} \mathrm{GS}\right)$ for $\mathrm{W}(\mathrm{CO})_{4}(\mathrm{bpy})$ are shown in Figure 1, while those of $\mathrm{Mo}(\mathrm{CO})_{4}(\mathrm{bpy})$ are found in Figure $\mathrm{S} 1$. The assignment of the character of the electronic states is based on the analysis of the orbitals involved in their corresponding TD-DFT electronic transitions, see Figures 1 and $\mathrm{S} 1$. For $\mathrm{W}(\mathrm{CO})_{4}(\mathrm{bpy})$ we obtained the following ES minima: four different ${ }^{3} \mathrm{MLCT}$ states involving the bpy ligand $\left({ }^{3} \mathrm{MLCT}_{\text {bpy }}(1-4)\right)$; one ${ }^{3} \mathrm{MLCT}$ state involving the axial CO ligands $\left({ }^{3} \mathrm{MLCT}_{\mathrm{CO}}\right)$; one ${ }^{3} \mathrm{LC}$ state; and one ${ }^{3} \mathrm{MC}$ state. ${ }^{3} \mathrm{MLCT}_{\mathrm{bpy}}(1)$ and ${ }^{3} \mathrm{MLCT}_{\mathrm{bpy}}(2)$ correspond to the lowest-lying triplet states. The optimized structures of the ${ }^{3} \mathrm{MLCT}_{\mathrm{bpy}}(1)$ and ${ }^{3} \mathrm{MLCT}_{\mathrm{bpy}}(2)$ states closely resemble the ${ }^{1} \mathrm{GS}$ geometry with regard to the octahedral coordination (see e.g., Figures $1 \mathrm{a}-\mathrm{c}$ ). ${ }^{3} \mathrm{MLCT}_{\mathrm{bpy}}(1)$ is characterized by stretched equatorial $\mathrm{M}-\mathrm{CO}$ bond distances $(2.04 \AA)$, while stretched axial M-CO bond distances $(2.10 \AA)$ are observed in the optimized geometry of ${ }^{3} \mathrm{MLCT}_{\mathrm{bpy}}(2)$. In addition, and due to the population of a $\pi *$ bpy orbital, the bpy bond ring distances strongly differ in the ${ }^{3} \mathrm{MLCT}_{\text {bpy }}(2)$ and ${ }^{1} \mathrm{GS}$ optimized structures (compare e.g., 1.47 with $1.43 \AA$ for the central C-C bond). In the following we discuss the optimized geometries of the rest of higher-lying states. First, the ${ }^{3} \mathrm{MLCT}_{\text {bpy }}(3)$ state displays similar features to those of ${ }^{3} \mathrm{MLCT}_{\mathrm{bpy}}(1)$. However, the optimized ${ }^{3} \mathrm{MLCT}_{\mathrm{bpy}}(3)$ structure is less symmetric than that of ${ }^{3} \mathrm{MLCT}_{\mathrm{bpy}}(1)$. This is because in the former complex only one pyridyl unit participates in $\pi *_{\text {bpy }}$ (see Figure $1 \mathrm{~d}$ ). Consequently, the optimized ${ }^{3} \mathrm{MLCT}_{\mathrm{bpy}}(3)$ geometry displays asymmetric $\mathrm{M}-\mathrm{N}$ bond distances (i.e., 2.26 and $2.28 \AA$ ). The optimized ${ }^{3} \mathrm{MC}$ structure is characterized by strong geometric distortions with respect to the ${ }^{1} \mathrm{GS}$ structure. Importantly both M-N bond distances are significantly stretched (amounting up to $2.51 \AA$ at ${ }^{3} \mathrm{MC}$, see Figure $1 \mathrm{e}$ ) and the equatorial C-O bond distances are slightly stretched due to mixing of equatorial $\pi * \mathrm{co}$ orbitals with the $e_{g}$-like metal $d$ orbital. Conversely, the optimized ${ }^{3}$ LC structure displays very similar features to those of the ${ }^{1} \mathrm{GS}$ structure. Not surprisingly, the main geometric distortions affect the bpy ligand. The optimized ${ }^{3} \mathrm{MLCT}_{\mathrm{CO}}$ structure involves the axial CO ligands (see Figure 1g), and therefore stretched axial M-CO distances are observed with respect to the ${ }^{1} \mathrm{GS}$ structure. Finally, the ${ }^{3} \mathrm{MLCT}_{\mathrm{bpy}}(4)$ states involves a lower-lying $\mathrm{t}_{2 \mathrm{~g}} \mathrm{~d}$ orbital and a higherlying $\pi *_{\text {bpy }}$ orbital. However, its optimized structure displays similar geometric characteristics to those observed for other ${ }^{3} \mathrm{MLCT}_{\text {bpy }}$ states. For $\mathrm{Mo}(\mathrm{CO})_{4}$ (bpy) we also obtained seven ES minima: ${ }^{3} \mathrm{MLCT}_{\text {bpy }}(1-4),{ }^{3} \mathrm{MC},{ }^{3} \mathrm{LC}$ and ${ }^{3} \mathrm{MLCT}_{\mathrm{CO}} /{ }^{3} \mathrm{MC}$ (see Figure S1). Five $\left({ }^{3} \mathrm{MLCT}_{\mathrm{bpy}}(1-3),{ }^{3} \mathrm{MC}\right.$ and ${ }^{3} \mathrm{LC}$ ) out of the seven ES minima are analogous to those of $\mathrm{W}(\mathrm{CO})_{4}(\mathrm{bpy})$. Conversely, for $\mathrm{Mo}(\mathrm{CO})_{4}(\mathrm{bpy})$, the ${ }^{3} \mathrm{MLCT}_{\mathrm{CO}}$ state is mixed with a ${ }^{3} \mathrm{MC}$ state (see the orbitals involved in Figure S1) and the ES minima of two different asymmetric ${ }^{3} \mathrm{MLCT}_{\text {bpy }}$ states were found $\left({ }^{3} \mathrm{MLCT}_{\mathrm{bpy}}(1-\right.$ $3)$ ). We recall that only one was found for $\mathrm{W}(\mathrm{CO})_{4}(\mathrm{bpy})$.

Table 2. Computed adiabatic relative energies for the different ES minima (with respect to the ${ }^{1} \mathrm{GS}$ minimum, in eV); and TD-DFT, $\triangle S C F-$ DFT and $\triangle$ SCF-DLPNO-CCSD(T) emission energies (in $\mathrm{cm}^{-1}$ )

\begin{tabular}{|c|c|c|c|c|}
\hline $\mathrm{W}(\mathrm{CO})_{4}(\mathrm{bpy})$ & $\begin{array}{l}\text { TD-DFT } \\
\text { (UDFT) } \\
\text { Relative } \\
\text { Energies }[\mathrm{eV}]^{\mathrm{a}}\end{array}$ & $\begin{array}{l}\text { TD-DFT (PCM-TD- } \\
\text { DFT) emission } \\
\text { energy }\left[\mathrm{cm}^{-1}\right]\end{array}$ & $\begin{array}{l}\Delta \text { SCF-DFT (PCM- } \\
\Delta \text { SCF-DFT) } \\
\text { emission energy } \\
{\left[\mathrm{cm}^{-1}\right]}\end{array}$ & $\begin{array}{l}\triangle S C F-D L P N O- \\
\text { CCSD(T) (solv) } \\
\text { emission energy } \\
{\left[\mathrm{cm}^{-1}\right]}\end{array}$ \\
\hline${ }^{3} \mathrm{MLCT}_{\mathrm{bpy}}(1)$ & $1.29(1.61)$ & 8756 (10693) & 10934 (12010) & 7990 (9066) \\
\hline${ }^{3} \mathrm{MLCT}_{\mathrm{bpy}}(2)$ & $1.47(1.68)$ & $9859(11604)$ & $10661(11723)$ & $8103(9166)$ \\
\hline${ }^{3} \mathrm{MLCT}_{\mathrm{bpy}}(3)$ & 2.27 & $16002(18243)$ & - & - \\
\hline${ }^{3} \mathrm{MC}$ & $1.69(2.23)$ & $-2930(-2445)$ & 2331(2808) & - \\
\hline${ }^{3} \mathrm{LC}$ & 2.75 & 19077 (19000) & - & - \\
\hline${ }^{3} \mathrm{MLCT}_{\mathrm{CO}}$ & 3.00 & $22339(20818)$ & - & - \\
\hline${ }^{3} \mathrm{MLCT}_{\text {bpy }}(4)$ & 4.16 & 32883 (32107) & - & - \\
\hline
\end{tabular}




\begin{tabular}{|c|c|c|c|c|}
\hline $\mathrm{Mo}(\mathrm{CO})_{4}(\mathrm{bpy})$ & $\begin{array}{l}\text { TD-DFT } \\
(\text { UDFT) } \\
\text { Relative } \\
\text { Energies }[\mathrm{eV}]^{\mathrm{a}}\end{array}$ & $\begin{array}{l}\text { TD-DFT (PCM-TD- } \\
\text { DFT) emission } \\
\text { energy }\left[\mathrm{cm}^{-1}\right]\end{array}$ & $\begin{array}{l}\Delta \text { SCF-DFT (PCM- } \\
\Delta \text { SCF-DFT) } \\
\text { emission energy } \\
{\left[\mathrm{cm}^{-1}\right]}\end{array}$ & $\begin{array}{l}\triangle S C F-D L P N O- \\
\text { CCSD(T) (solv) } \\
\text { emission energy } \\
{\left[\mathrm{cm}^{-1}\right]}\end{array}$ \\
\hline${ }^{3} \mathrm{MLCT}_{\text {bpy }}(1)$ & $1.41(1.74)$ & 9521 (11499) & 11043 (12036) & $9172(10164)$ \\
\hline${ }^{3} \mathrm{MLCT}_{\text {bpy }}(2)$ & $1.56(1.82)$ & 10394 (12210) & 11704 (12713) & 9207 (10217) \\
\hline${ }^{3} \mathrm{MLCT}_{\text {bpy }}(3)$ & 2.38 & 16885 (19153) & - & - \\
\hline${ }^{3} \mathrm{MLCT}_{\mathrm{bpy}}(4)$ & 2.51 & 17984 (19890) & & - \\
\hline${ }^{3} \mathrm{MC}$ & 1.72 & $-2645(-2165)$ & - & - \\
\hline${ }^{3} \mathrm{LC}$ & 2.74 & 18858 (18839) & - & - \\
\hline${ }^{3} \mathrm{MLCT}_{\mathrm{CO}} /^{3} \mathrm{MC}$ & 2.78 & 18831 (18898) & - & - \\
\hline
\end{tabular}

The seven TD-DFT optimized geometries served as initial guesses for subsequent UDFT optimizations (see computational details in the Experimental Section). With the latter computational protocol, for $\mathrm{W}(\mathrm{CO})_{4}(\mathrm{bpy})$ only three (i.e., ${ }^{3} \mathrm{MLCT}_{\mathrm{bpy}}(1),{ }^{3} \mathrm{MLCT}_{\mathrm{bpy}}(2)$ and ${ }^{3} \mathrm{MC}$ ) out of the seven triplet states converged into their original triplet ESs. Conversely, the optimizations starting from the other four higher-lying states ended up in lower-lying ES minima due to the variational collapse of the wavefunction at the UDFT level. In the case of $\mathrm{Mo}(\mathrm{CO})_{4}(\mathrm{bpy})$, only the re-optimizations for the ${ }^{3} \mathrm{MLCT}_{\mathrm{bpy}}(1)$ and ${ }^{3} \mathrm{MLCT}_{\mathrm{bpy}}(2)$ states were successful. Similar geometric features are observed between the TD-DFT and UDFT optimized geometries (see Figures S2-S3 for comparisons). Thus, the analysis of these results hints that ${ }^{3} \mathrm{MLCT}_{\text {bpy }}(1),{ }^{3} \mathrm{MLCT}_{\text {bpy }}(2)$ and ${ }^{3} \mathrm{MC}$ are true minima in the lowest adiabatic triplet $\mathrm{PES}$, at least for $\mathrm{W}(\mathrm{CO})_{4}(\mathrm{bpy})$, while the other minima belong to higher-lying triplet PESs. In Table 2 we collect the computed i) adiabatic relative energies between all the states and ii) the emission energies from all possible triplet ES minima for $\mathrm{W}(\mathrm{CO})_{4}(\mathrm{bpy})$ and $\mathrm{Mo}(\mathrm{CO})_{4}(\mathrm{bpy})$. The adiabatic relative energies further confirm that ${ }^{3} \mathrm{MLCT}_{\mathrm{bpy}}(1)$ and ${ }^{3} \mathrm{MLCT}_{\mathrm{bpy}}(2)$ are the lowest-lying triplet ESs. They are adiabatically located within 0.07 and $0.08 \mathrm{eV}$ (see UDFT values in Table 2), so that both states are likely thermally-equilibrated at room temperature. In Table 2 are also collected both the gas phase and solvent corrected i) TD-DFT emission energies for all possible emitting states; and ii) $\triangle$ SCF-DFT emission energies for the ${ }^{3} \mathrm{MLCT}_{\mathrm{bpy}}(1),{ }^{3} \mathrm{MLCT}_{\mathrm{bpy}}(2)$ and ${ }^{3} \mathrm{MC}$ states. The variational collapse of the wavefunction for the other four states refrain us to compute their $\triangle$ SCF-DFT emission energies. An inspection of the computed emission energies reveals that the ${ }^{3} \mathrm{MC}$ is not responsible for any of the experimentally observed emission bands simply because the computed values are too low (see e.g., the PCM- $\triangle$ SCF-DFT values of 2808 $\mathrm{cm}^{-1}$ for $\mathrm{W}(\mathrm{CO})_{4}$ (bpy). Indeed, ${ }^{3} \mathrm{MC}$ states are generally believed not to be involved in emission processes. Instead, they play an important role in non-radiative deactivation mechanisms, ${ }^{26}$ mediated $v i a{ }^{3} \mathrm{MC} /{ }^{1} \mathrm{GS}$ minimum energy crossing points. ${ }^{27,28}$ Therefore, in view of the computed values, the states responsible for the LE band are the lowest-lying ${ }^{3} \mathrm{MLCT}_{\mathrm{bpy}}(1)$ and ${ }^{3} \mathrm{MLCT}_{\mathrm{bpy}}(2)$ states. Very similar PCM- $\Delta$ SCF-DFT emission energies are computed for these two states, compare e.g., 12010 and $11723 \mathrm{~cm}^{-1}$ for the ${ }^{3} \mathrm{MLCT}_{\mathrm{bpy}}(1)$ and ${ }^{3} \mathrm{MLCT}_{\mathrm{bpy}}(2)$ states of $\mathrm{W}(\mathrm{CO})_{4}(\mathrm{bpy})$; values which are in good agreement with the LE band maximum $\left(12970 \mathrm{~cm}^{-1}\right)$. Conversely, the computed PCM-TD-DFT values are slightly underestimated with respect to the PCM- $\triangle$ SCF-DFT values and the experimental values. The emissions from the ${ }^{3} \mathrm{MLCT}_{\mathrm{bpy}}(1)$ and ${ }^{3} \mathrm{MLCT}_{\mathrm{bpy}}(2)$ states overlap and result in a single band in the experimental spectra, but indeed two different lifetimes are measured for the LE band (see discussion above). Further theoretical insights towards unambiguously assigning the LE band are presented in the following. More in details, single point singlet and triplet DLPNO-CCSD $(T) / C B S$ calculations on the ${ }^{3} \mathrm{MLCT}_{\text {bpy }}(1)$ and ${ }^{3} \mathrm{MLCT}_{\text {bpy }}(2)$ optimized geometries were performed (see the computed energy values in Table 2 and the computational details in the Experimental Section). The DLPNO-CCSD(T) method is considered to be the goldstandard method for transition metal complexes, ${ }^{29}$ and has shown to yield accurate results provided the investigated systems lack of multireference character. ${ }^{30}$ Our DLPNO-CCSD(T)/CBS emission energies are slightly underestimated with respect to the experimental values but also point to both ${ }^{3} \mathrm{MLCT}_{\mathrm{bpy}}(1)$ and ${ }^{3} \mathrm{MLCT}_{\mathrm{bpy}}(2)$ to be responsible for the LE band for both complexes. We now turn the discussion to the assignment of the HE band. As discussed above, previous investigations hypothesized the ${ }^{3} \mathrm{MC}$ and ${ }^{3} \mathrm{MLCT}$ co to be responsible for this band. Instead, in view of our computed adiabatic relative energies and the PCM-TD-DFT emission energy values, the ${ }^{3} \mathrm{MLCT}_{\text {byy }}(3)$ state is likely responsible for the HE band (compare e.g., the computed emission maxima of 18243 and $19153 \mathrm{~cm}^{-1}$ with the experimental values of 17030 and $17300 \mathrm{~cm}^{-1}$ for $\mathrm{W}(\mathrm{CO})_{4}(\mathrm{bpy})$ and $\mathrm{Mo}(\mathrm{CO})_{4}(\mathrm{bpy})$; respectively). Other possible emissive states (i.e., ${ }^{3} \mathrm{MLCT} \mathrm{Co}_{\mathrm{C}}{ }^{3} \mathrm{MLCT} \mathrm{Co} /{ }^{3} \mathrm{MC},{ }^{3} \mathrm{LC}$ and ${ }^{3} \mathrm{MLCT}_{\mathrm{bpy}}(4)$ ) are ruled out in view of their larger adiabatic relative energies with respect to ${ }^{3} \mathrm{MLCT}_{\text {bpy }}(3)$, but also due to their larger computed emission energies (in most of the cases). For the phenanthroline-based $\mathrm{W}(\mathrm{CO})_{4}(\mathrm{phen})$ and $\mathrm{W}(\mathrm{CO})_{4}(\operatorname{tmp})$ complexes, time-resolved experiments concluded that the HE likely originates in several radiative transitions. ${ }^{25}$ 
However, in the case of our bpy complexes this option appears less plausible in view of the computed evidences; since only one triplet ES minimum was obtained in the 2.2-2.4 eV energy window, i.e., ${ }^{3} \mathrm{MLCT}_{\mathrm{bpy}}(3)$ state. In a nutshell, these theoretical investigations highlight that the breaking of Kasha's rule in $\left[\mathrm{M}(\mathrm{CO})_{4}(\mathrm{bpy})\right]$ complexes is at least two-fold, because two different excited states besides $T_{1}$ are involved in emission.

In the following we discuss the likely origins for the anti-Kasha emissions observed in $\left[\mathrm{W}(\mathrm{CO})_{4}(\mathrm{bpy})\right]$ and $\left[\mathrm{Mo}(\mathrm{CO})_{4}(\mathrm{bpy})\right]$. Exemplarily, the schematic Jablonski diagram displaying all possible triplet ES minima for $\left[\mathrm{W}(\mathrm{CO})_{4}(\mathrm{bpy})\right]$ is shown in Figure 2. Note that ${ }^{3} \mathrm{MLCT}_{\text {bpy }}(4)$ is disregarded in view of its large adiabatic relative energy $(>4.0 \mathrm{eV}$ ) and thus, it will likely not be populated under the experimental conditions. The lowest adiabatic triplet PES is depicted in red. Upon excitation of the manifold of singlet ES $\left(S_{n}\right)$ relatively fast ISC processes populating the manifold of triplet ESs $\left(T_{n}\right)$ occur. From there two possibilities arise: i) population of the lowest adiabatic triplet PES through IC processes and ii) population of the wells of different higher-lying triplet ES (i.e., ${ }^{3} \mathrm{MLCT}_{\text {bpy }}(3) ;{ }^{3} \mathrm{LC}$ and ${ }^{3} \mathrm{MLCT}_{\mathrm{CO}}$ in the case of $\left.\left[\mathrm{W}(\mathrm{CO})_{4}(\mathrm{bpy})\right]\right)$. The large adiabatic energy gaps between these three states and the lowest triplet ES (of ca. $>0.8 \mathrm{eV}$, see Table 2) are responsible for slowing down the IC processes to the lowest triplet ES. Therefore, emission of a photon from ${ }^{3} \mathrm{MLCT}_{\mathrm{bpy}}(3)$, which is the lowest adiabatic state in the high-energy window, is competitive with IC, leading to the HE band (see Figure 2). Note that for this band, emissions arising from the ${ }^{3} \mathrm{LC}$ and ${ }^{3} \mathrm{MLCT}_{\mathrm{CO}}$ are less plausible due to their smaller (but non-negligible) energy gaps with ${ }^{3} \mathrm{MLCT}_{\mathrm{bpy}}(3)$, which on the one hand side promote fast IC processes to ${ }^{3} \mathrm{MLCT}_{\mathrm{bpy}}(3)$, and on the other hand side prevent that those triplet $\mathrm{ES}$ will be thermally equilibrated with ${ }^{3} \mathrm{MLCT}_{\mathrm{bpy}}(3)$. $\left[\mathrm{Mo}(\mathrm{CO})_{4}(\mathrm{bpy})\right]$ shows very similar features, differing only in the character of some of the higher-lying ESs; so that the above discussion is also valid for this complex.

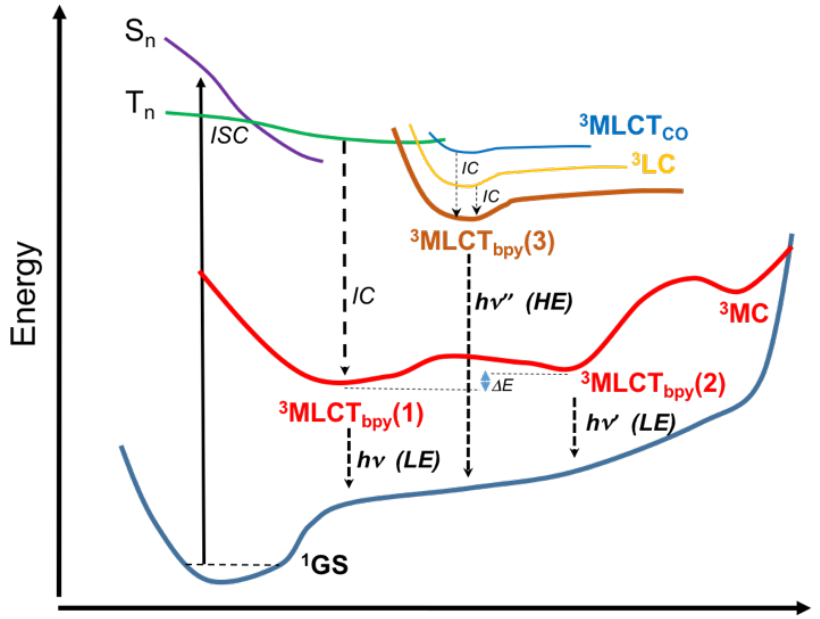

Reaction coordinate

Figure 2. Schematic Jablonski diagram for $\left[\mathrm{W}(\mathrm{CO})_{4}(\mathrm{bpy})\right]$

The above discussed HE emission can be catalogued as a non-thermally equilibrated anti-Kasha scenario. This scenario also explains the experimentally observed excitation wavelength-dependent emissive characteristics of $\left[\mathrm{M}(\mathrm{CO})_{4}(\mathrm{bpy})\right]$ complexes. Besides these "hot" photoemissions, some of the ES population will decay to the lowest adiabatic triplet PES through IC, from where emission from the ${ }^{3} \mathrm{MLCT}_{\mathrm{bpy}}(1)$ and ${ }^{3} \mathrm{MLCT}_{\mathrm{bpy}}(2)$ states will occur, leading to the LE band. Dual emission from the ${ }^{3} \mathrm{MLCT}_{\mathrm{bpy}}(1)$ and ${ }^{3} \mathrm{MLCT}_{\mathrm{bpy}}(2)$ states is feasible due to $\left.\mathrm{i}\right)$ the small energy gap between these states $(\Delta \mathrm{E}<0.08 \mathrm{eV})$, so that these states are thermally equilibrated at room temperature and ii) the rather similar radiative decay rates from both states. Therefore, this second anti-Kasha scenario corresponds to a thermally-equilibrated one. In a nutshell, $\left[\mathrm{M}(\mathrm{CO})_{4}(\mathrm{bpy})\right](\mathrm{M}=\mathrm{Mo}, \mathrm{W})$ complexes are demonstrated to display both equilibrated and non-equilibrated anti-Kasha emissions. To complete their complex photoreactivity, we note that other triplet ES besides the emissive states might be populated on the course of photodeactivation. These alternative "hot" photoreactivity channels might be involved e.g., in the nonradiative deactivation to the ${ }^{1} \mathrm{GS}$ (through e.g., the ${ }^{3} \mathrm{MC}$ state, see Figure 2) or in the experimentally observed excitation wavelength-dependent photochemical substitution of an axial CO ligand (through e.g., the population of the ${ }^{3} \mathrm{MLCT}_{\mathrm{CO}}$ state and/or other possible dissociative states).

\section{Conclusion}


Despite their apparent structural simplicity, $\left[\mathrm{M}(\mathrm{CO})_{4}(\mathrm{bpy})\right](\mathrm{M}=\mathrm{Mo}, \mathrm{W})$ complexes possess rich and chameleonic photochemical properties, which make them the ideal case studies for in-depth theoretical investigations. In this contribution, the triplet ES PES of these complexes have been explored with high-level ab initio coupled-cluster and TD-DFT calculations. Our investigations have helped to unambiguously unravel the origins of their complex emissive characteristics. These studies highlight that in the $\left[\mathrm{M}(\mathrm{CO})_{4}(\mathrm{bpy})\right]$ series, the breaking of Kasha's rule is at least two-fold. Hence, different anti-Kasha scenarios (equilibrated vs non-equilibrated ones) are demonstrated to simultaneously coexist in the same complex. Thus, to our knowledge, these are the first transition metal complexes demonstrated to display simultaneous equilibrated and non-equilibrated anti-Kasha emissions, besides the Kasha-like emission from $T_{1}$. This work also highlights the complexity of the photodeactivation channels in transition metal complexes and it contributes to put on firmer grounds anti-Kasha events, which are still a matter of debate in the community partially due to the lack of in-depth experimental photochemical investigations performed on a routine basis (e.g., excitation wavelength- and temperature-dependent emission experiments). From a theoretical viewpoint, we remark the capability of UDFT and TD-DFT methods to studying complex emissive scenarios involving not only the lowest adiabatic triplet ES (accessible with UDFT) but also higher-lying ESs (accessible with TD-DFT). Due to the increasing number of reported violations of Kasha rule in the literature, it also raises an urgent debate in the theoretical inorganic photochemistry community on the need to exhaustively explore higher-lying ES PES in a routine basis to model emissive processes. Currently, the common strategy in the community consists of optimizing only the geometry of $T_{1}$, from where Kasha-like emission is always believed to take place. As shown here, this latter strategy is not appropriate in complex photochemical scenarios, such as those of e.g., $\left[\mathrm{M}(\mathrm{CO})_{4}(\mathrm{bpy})\right]$ complexes, but also in the case that the lowest $\mathrm{ES}$ is a dark state. ${ }^{31}$

\section{Experimental Section}

Computational Details: Singlet ground-state equilibrium structures of the two tetracarbonyl-diimine transition metal complexes $\left(\left[\mathrm{W}(\mathrm{CO})_{4}(\mathrm{bpy})\right]\right.$ and $\left[\mathrm{Mo}(\mathrm{CO})_{4}(\mathrm{bpy})\right]$ ) were optimized using the B3LYP functional $\left.\right|^{32,33}$ and the $6-31 \mathrm{G}^{*}$ basis set. To account for relativistic effects the pseudopotentials MWB28 and MWB60 where used for Mo and W, respectively. ${ }^{34}$ Higher lying excited triplet state structures of both complexes where optimized with TD-DFT ${ }^{35}$ and using the same functional and basis sets as in the singlet ground state optimizations. In addition, the seven TD-DFT optimized geometries served as initial guesses for subsequent UDFT optimizations, using the same functional and basis sets as in the rest of optimizations. Due to the variational collapse of the wavefunction for some of the states, only three different triplet ES minima were obtained with the latter protocol (i.e.., ${ }^{3} \mathrm{MLCT}_{\text {bpy }}(1)$, ${ }^{3} \mathrm{MLCT}_{\text {bpy }}(2)$ and $\left.{ }^{3} \mathrm{MC}\right)$. The phosphorescence emission spectra were simulated on the basis of $\triangle$ SCF-B3LYP calculations and/or singlet-triplet TD-B3LYP excitations at their triplet optimized geometries using the same basis sets as in the rest of the optimizations. To model solvent effects, phosphorescence spectra were also computed within the standard PCM framework (solvent=benzene). ${ }^{36}$ All above mentioned calculations were performed with Gaussian. ${ }^{37}$ Furthermore, aiming at a highest accuracy for the LE band, singlet and triplet DLPNO-CCSD $(T)^{38}$ single point calculations with complete basis set extrapolation (CBS) where performed (i.e., Extrapolate(2/3,def2) def2-XVP/C) at the UDFT optimized geometries of ${ }^{3} \mathrm{MLCT}_{\text {bpy }}(1)$ and ${ }^{3} \mathrm{MLCT}_{\text {bpy }}(2)$. These calculations made used of the normal PNO settings. Solvent corrections computed at the PCM-UDFT level of theory where added to the DLPNO-CCSD(T)/CBS values. The CC calculations were carried out with the Orca program package. ${ }^{39}$

\section{Acknowledgements}

D. E. acknowledges internal KU Leuven funds.

Keywords: Kasha rule $\bullet$ inorganic photophysics $\cdot$ TD-DFT $•$ computational photochemistry $•$ photoluminescence

\section{References}

\footnotetext{
${ }^{1}$ M. Kasha, Faraday Soc. 1950, $9,14-19$

2 (PAC, 2007, 79, 293 (Glossary of terms used in photochemistry, 3rd edn (IUPAC Recommendations 2006)) on page 360.) IUPAC. Compendium of ChemicalTerminology, 2nd edn (the "Gold Book"). Compiled by A. D. McNaught and A. Wilkinson. Blackwell Scientific Publications, Oxford (1997). XML on-line corrected version: http://goldbook.iupac.org (2006) created by M. Nic, J. Jirat, B. Kosata; updates compiled by A. Jenkins. ISBN 0-9678550-9-8, https://doi.org/10.1351/goldbook.

${ }^{3}$ T. Itoh, Chem. Rev. 2012, 112, $4541-4568$

${ }^{4}$ M. Beer, H. C. Longuet-Higgins, J. Chem. Phys. 1955, 23, $1390-1391$

${ }^{5}$ G. Viswanath, M. Kasha, J. Chem. Phys. 1956, 24, $574-577$

${ }^{6}$ K. E. Henry, R. G. Balasingham, A. R. Vortherms, J. A. Platts, J. F. Valliant, M. P. Coogan, J. Zubieta, R. P. Doyle, Chem. Sci. 2013, 4, $2490-2495$
} 
${ }^{7}$ A. P. Demchenko, V. I. Tomin, P. T. Chou, Chem. Rev. 2017, 117, $13353-13381$

8 J. C. del Valle, J. Catalán, Phys. Chem. Chem. Phys. 2019, 21, 10061-10069

${ }^{9}$ D. Escudero in Transition Metals in Coordination Environments. Computational Chemistry and Catalysis View points (Eds.: E. Broclawik et al.), Springer International Publishing Switzerland, 2019, pp. 259-287.

${ }^{10}$ D. N. Kozhevnikov, V. N. Kozhevnikov, M. Z. Shafikov, A. M. Prokhorov, D. W. Bruce, J. A. Gareth Williams, Inorg. Chem. 2011, 50, 380 $-3815$

${ }^{11}$ S. Kumar, Y. Hisamatsu, Y. Tamaki, O. Ishitani, S. Aoki, Inorg. Chem. 2016, 55, 3829 - 3843

${ }^{12}$ Y.-S. Yeh, Y.-M Cheng, P.-T. Chou, G.-H. Lee, C.-H. Yang, Y. Chi, C.-F. Shu, C.-H. Wang, ChemPhysChem 2006, 7, 2294 - 2297

${ }^{13}$ S. Ladouceur, L. Donato, M. Romain, B. P. Mudraboyina, M. B. Johansen, J. A. Wisner, E. Zysman-Colman, Dalton Trans. 2013, 42, 8838 $-8847$

${ }^{14}$ D. Escudero, W. Thiel, Inorg. Chem. 2014, 53, $11015-11019$

15 P. Irmler, F. S. Gogesch, A. Mang, M. Bodensteiner, C. B. Larsen, O. S. Wenger, R. F. Winter, Dalton Trans. 2019, DOI:10.1039/C9DT01737B

${ }^{16}$ J. M. Favale, E. O. Danilov, J. E. Yarnell, F. N. Castellano, Inorg. Chem. 2019, 58, 8750 -8762

${ }^{17}$ C.-C. Hsu, C.-C. Lin, P.-T. Chou, C.-H. Lai, C.-W. Hsu, C.-H. Lin, Y. Chi, J. Am. Chem. Soc. 2012, $134,7715-7724$

${ }^{18}$ D. Magde, M. D. Magde Jr., E. C. Glazer, Coord. Chem. Rev. 2016, 306, 447 - 467

${ }^{19}$ D. Jacquemin, D. Escudero, Phys. Chem. Chem. Phys. 2018, 20, $11559-11563$

${ }^{20}$ A. J. Lees, Chem. Rev. 1987, 87, 711 - 743

${ }^{21}$ D. M. Manuta, A. J. Lees, Inorg. Chem. 1986, 25, 1354 - 1359

${ }^{22}$ M. L. Clark, K. A. Grice, C. E. Moore, A. L. Rheingold, C. P. Kubiak, Chem. Sci. 2014, 5, 1894 - 1900

${ }^{23}$ J. O. Taylor, R. D. Leavey, F. Hartl, ChemElectroChem 2018, 5, 3155 - 3161

${ }^{24}$ A. Vlcek Jr. Coord. Chem. Rev. 2002, 230, 225 - 242

${ }^{25}$ I. R. Farrell, J. van Slageren, S. Zális, A. Vlcek Jr. Inorganica Chim. Acta 2001, 315, 44 - 52

${ }^{26}$ P. S. Wagenknecht, P. C. Ford, Coord. Chem. Rev. 2011, 255, 591 - 616

${ }^{27}$ D. Escudero, E. Heuser, R. J. Meier, M. Schäferling, W. Thiel, E. Holder, Chem. Eur. J. 2013, 19, 15639 -15644

${ }^{28}$ X. Zhang, D. Jacquemin, Q. Peng, Z. Shuai, D. Escudero, J. Phys. Chem. C 2018, 122, $6340-6347$

${ }^{29}$ D. G. Liakos, M. Sparta, M. K. Kesharwan, J. M. L. Martin, F. Neese, J. Chem. Theory Comput. 2015, 11, 1525 - 1539

${ }^{30}$ T. Husch, L. Freitag, M. Reiher, J. Chem. Theory Comput. 2018, 14, $2456-2468$

${ }^{31}$ D. Escudero, Acc. Chem. Res. 2016, 49, 1816 - 1824

${ }^{32}$ A. D. Becke, J. Chem. Phys. 1993, 98, 5648

${ }^{33}$ C. T. Lee, W. T. Yang, R. G. Parr, Phys. Rev. B, 1988, 37, 785-789

${ }^{34}$ D. Andrae, U. Häusermann, M. Dolg, H. Stoll, H. Preuss, Theor. Chim. Acta 1990, 77, 123-141

${ }^{35}$ M. E. Casida, M. Huix-Rotllant, Annu. Rev. Phys. Chem. 2012, 63, 287-323

${ }^{36}$ J. Tomasi, B. Mennucci, R. Cammi, Chem. Rev. 2005, 105, 2999- 3094

${ }^{37}$ G. M. J. Frisch, et al. Gaussian 09, Revision A.1, Gaussian, Inc., Wallingford CT, 2009.

${ }^{38}$ C. Riplinger, B. Sandhoefer, A. Hansen, F. Neese, J. Chem. Phys. 2013, 139, 134101

${ }^{39}$ F. Neese, Orca, an ab initio, DFT and semiempirical SCF-MO package 2.8.0 R2327; University of Bonn: Bonn, Germany, 2011 


\title{
Supporting Information
}

\section{Multiple Anti-Kasha emissions in transition metal complexes}

\author{
Milena Röhrs, Daniel Escudero ${ }^{a *}$
}

\author{
${ }^{a}$ Prof. Daniel Escudero \\ Department of Chemistry, KU Leuven, Celestijnenlaan 200F, B-3001 Leuven, Belgium \\ Website : https://chem.kuleuven.be/en/research/qcpc/cpc/ \\ E-mail: daniel.escudero@kuleuven.be
}

1. Figures S1-S3

2. Cartesian coordinates page $2-4$

page $5-17$ 


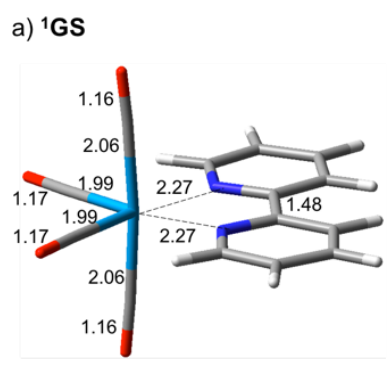

e) ${ }^{3} \mathrm{MLCT}_{\mathrm{bpy}}(4)$

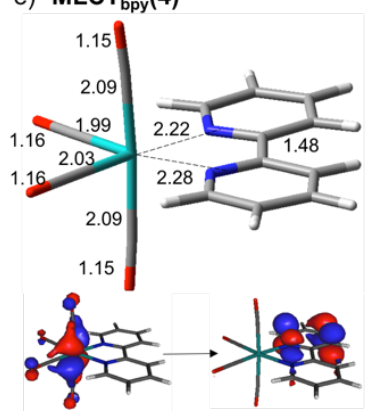

b) ${ }^{3} \mathrm{MLCT}_{\text {bpy }}(1)$

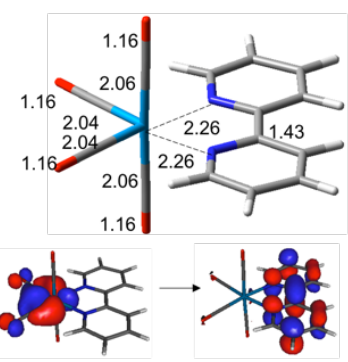

f) ${ }^{3} \mathrm{MC}$

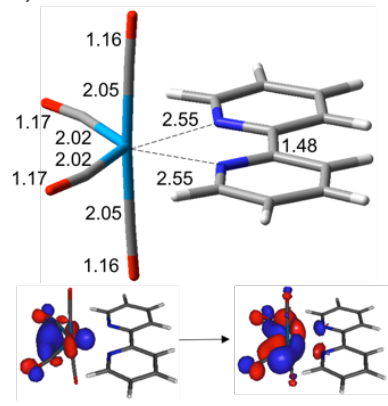

c) ${ }^{3} \mathrm{MLCT}_{\mathrm{bpy}}(2)$

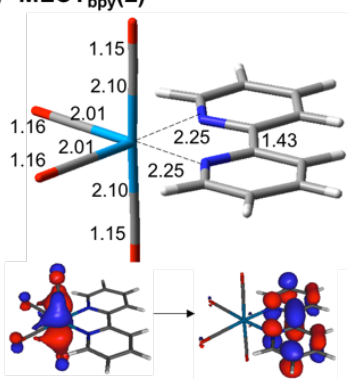

d) ${ }^{3} \mathrm{MLCT}_{\text {bpy }}(3)$

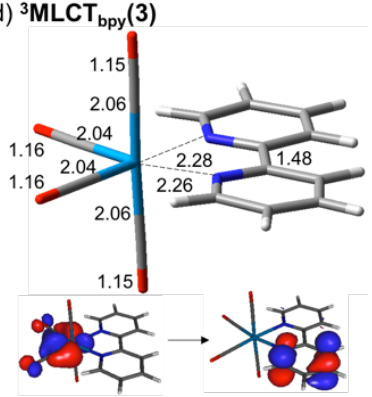

g) ${ }^{3} \mathrm{LC}$

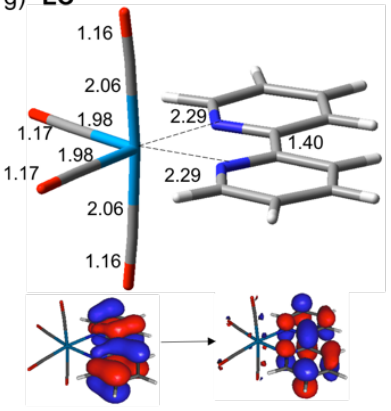

h) ${ }^{3} \mathrm{MLCT}_{\mathrm{Co}}{ }^{3} \mathrm{MC}$

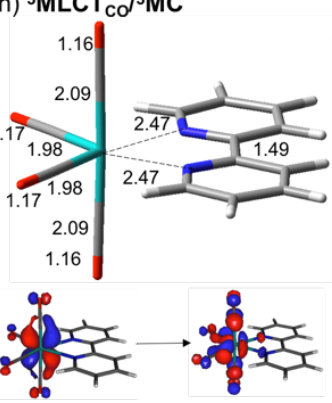

Figure S1. Main geometrical features of the optimized structures of ${ }^{1} \mathrm{GS},{ }^{3} \mathrm{MLCT}_{\text {bpy }}(1),{ }^{3} \mathrm{MLCT}_{\text {bpy }}(2)$, ${ }^{3} \mathrm{MLCT}_{\text {bpy }}(3),{ }^{3} \mathrm{MLCT}_{\text {bpy }}(4),{ }^{3} \mathrm{MC},{ }^{3} \mathrm{LC},{ }^{3} \mathrm{MLCT}_{\mathrm{co}} /{ }^{3} \mathrm{MC}$ for $\mathrm{Mo}(\mathrm{CO})_{4}(\mathrm{bpy})$. Below each optimized structure are shown the orbitals involved in their corresponding TD-DFT electronic transitions. Bond distances are given in $\AA$. 
${ }^{3} \mathrm{MLCT}_{\mathrm{bpy}}(1)$-TD-DFT (opt)

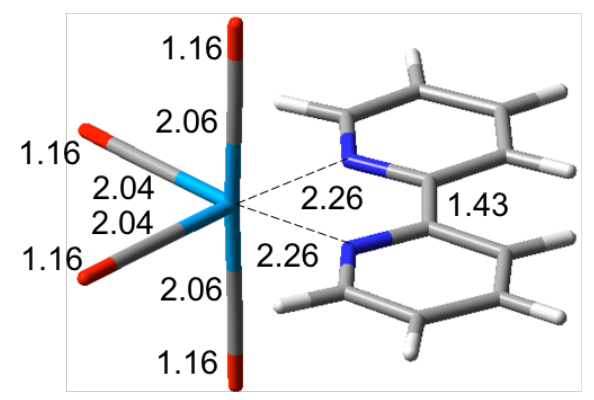

${ }^{3} \mathrm{MLCT}_{\text {bpy }}(2)-\mathrm{TD}-\mathrm{DFT}$ (opt)

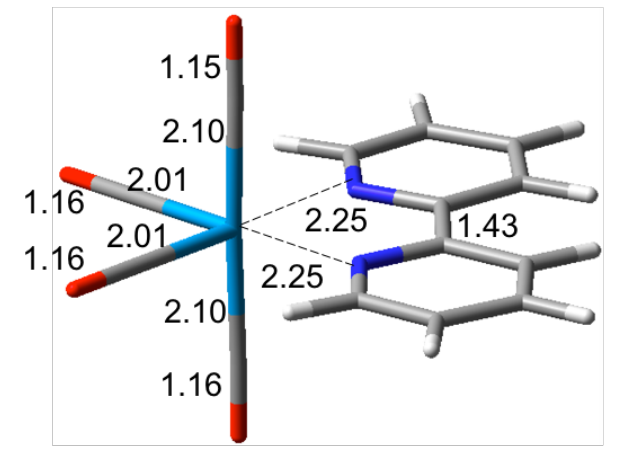

$$
{ }^{3} \mathrm{MC}-\mathrm{TD}-\mathrm{DFT} \text { (opt) }
$$

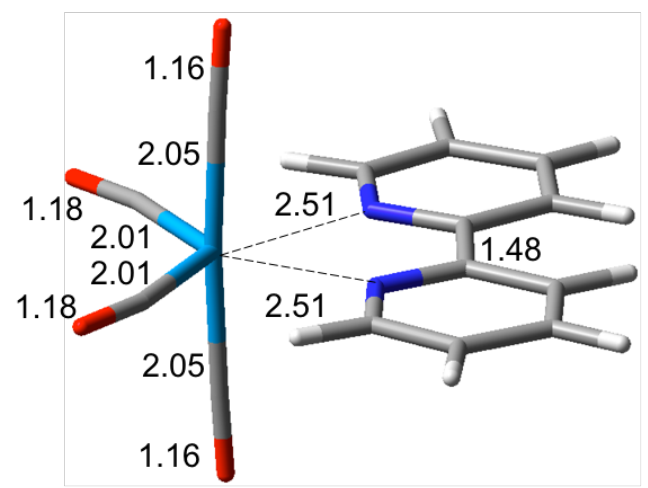

${ }^{3} \mathrm{MLCT}_{\mathrm{bpy}}(1)$-UDFT (opt)

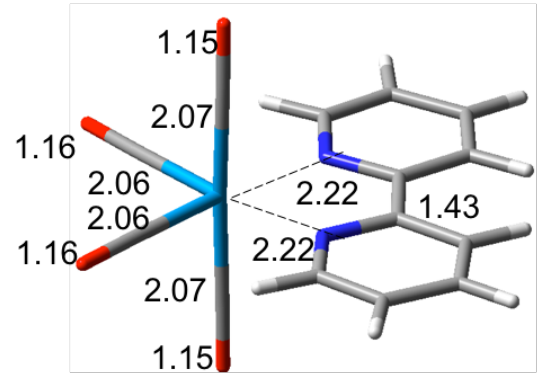

${ }^{3} \mathrm{MLCT}_{\text {bpy }}(2)$-UDFT (opt)

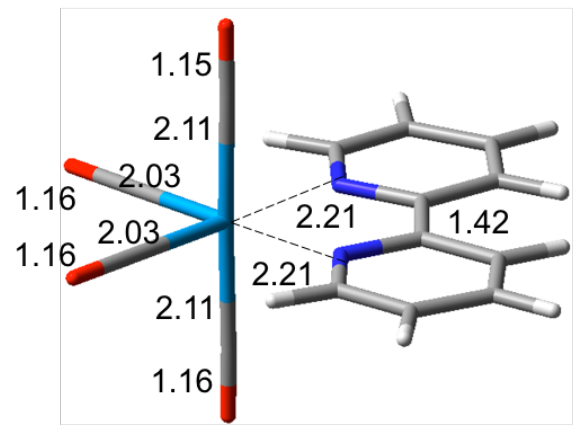

${ }^{3} \mathrm{MC}$-UDFT (opt)

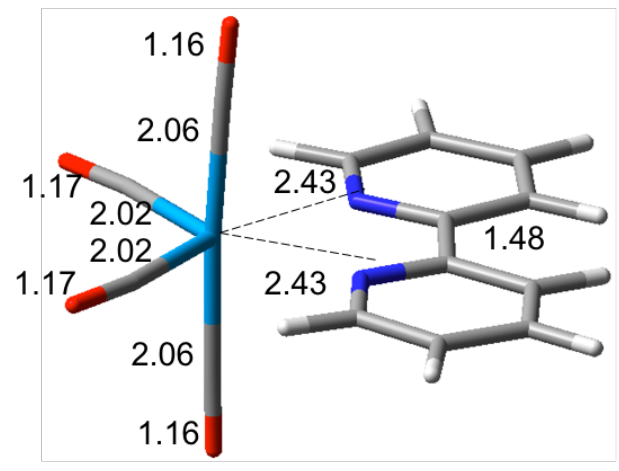

Figure S2. Comparison of the ES minima optimized with TD-DFT and UDFT for $W(C O)_{4}(b p y)$. 
${ }^{3} \mathrm{MLCT}_{\text {bpy }}(1)-\mathrm{TD}-\mathrm{DFT}$ (opt)

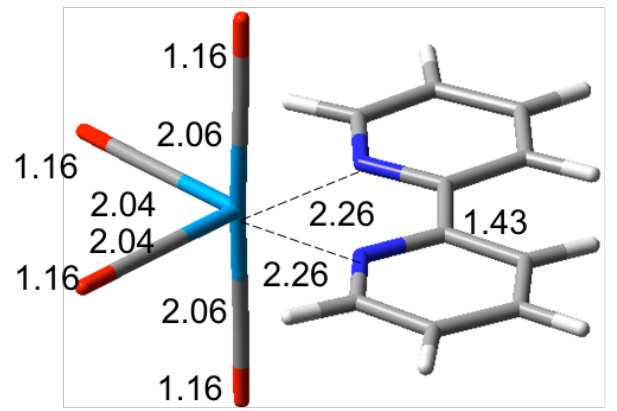

${ }^{3} \mathrm{MLCT}_{\mathrm{bpy}}(2)-\mathrm{TD}-\mathrm{DFT}$ (opt)

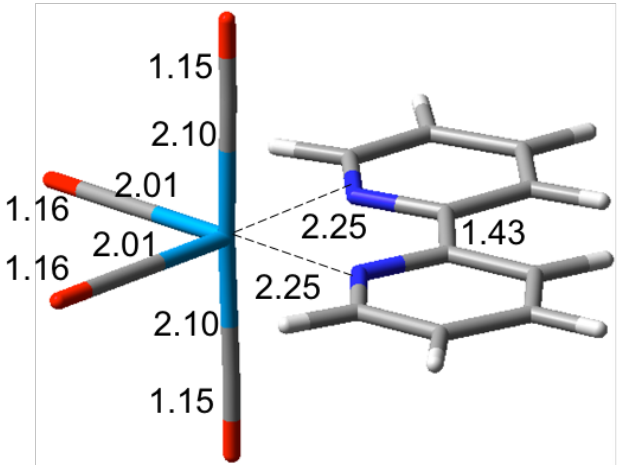

${ }^{3} \mathrm{MLCT}_{\text {bpy }}(1)$-UDFT (opt)

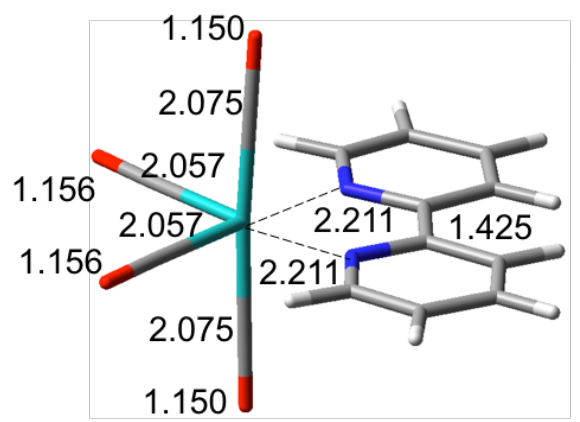

${ }^{3} \mathrm{MLCT}_{\mathrm{bpy}}(2)-\mathrm{UDFT}$ (opt)

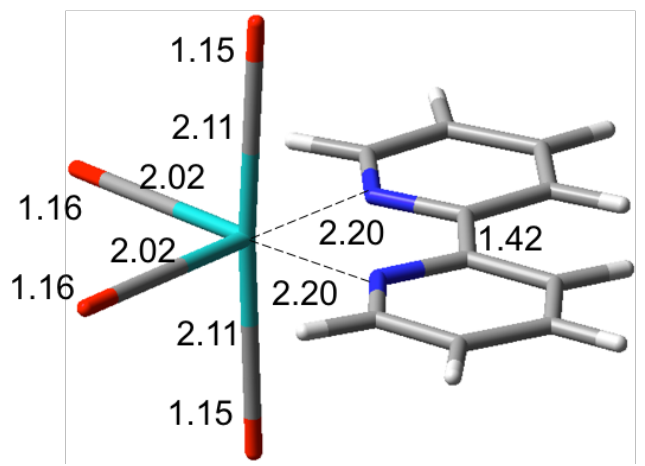

Figure S3. Comparison of the ES minima optimized with TD-DFT and UDFT for $\mathrm{Mo}(\mathrm{CO})_{4}(\mathrm{bpy})$. 
${ }^{1}$ GS - W(CO)4(bpy)

$\begin{array}{rrrr}\text { W } & 0.322174 & 0.256575 & -0.676599 \\ \mathrm{C} & 3.166575 & 1.577675 & -0.359825 \\ \mathrm{C} & 3.197962 & -0.609643 & 0.446120 \\ \mathrm{C} & 4.522353 & 1.727832 & -0.038802 \\ \mathrm{C} & 2.356431 & 2.646152 & -0.972587 \\ \mathrm{C} & 4.540431 & -0.521262 & 0.786676 \\ \mathrm{H} & 2.631081 & -1.516777 & 0.619654 \\ \mathrm{C} & 5.218914 & 0.673857 & 0.538779 \\ \mathrm{H} & 5.031312 & 2.662947 & -0.239278 \\ \mathrm{C} & 2.865498 & 3.913252 & -1.287310 \\ \mathrm{H} & 5.037279 & -1.374509 & 1.235941 \\ \mathrm{H} & 6.269346 & 0.782496 & 0.790294 \\ \mathrm{C} & 0.259542 & 3.266481 & -1.780371 \\ \mathrm{C} & 2.038169 & 4.869653 & -1.862176 \\ \mathrm{H} & 3.902551 & 4.151670 & -1.083940 \\ \mathrm{C} & 0.705256 & 4.537760 & -2.113792 \\ \mathrm{H} & -0.766173 & 2.964989 & -1.957322 \\ \mathrm{H} & 2.425074 & 5.853557 & -2.108552 \\ \mathrm{H} & 0.017153 & 5.247368 & -2.560671 \\ \mathrm{C} & -0.287714 & 0.880386 & 1.193118 \\ \mathrm{C} & -1.569951 & 0.459547 & -1.285083 \\ \mathrm{C} & 0.769978 & -0.489917 & -2.547014 \\ \mathrm{C} & 0.014150 & -1.623449 & -0.075525 \\ \mathrm{O} & -2.662374 & 0.641299 & -1.659637 \\ \mathrm{O} & 0.974459 & -0.944101 & -3.594555 \\ \mathrm{O} & -0.100049 & -2.725900 & 0.296434 \\ \mathrm{O} & -0.675853 & 1.194884 & 2.239944 \\ \mathrm{~N} & 1.055189 & 2.328720 & -1.221216 \\ \mathrm{~N} & 2.511131 & 0.408690 & -0.116242\end{array}$

${ }^{3} \mathrm{MLCT}_{\text {bpy }}(1)$ - W(CO)4(bpy)

\begin{tabular}{rrrr} 
W & 0.313820 & \multicolumn{1}{c}{0.250494} & \multicolumn{1}{c}{-0.674819} \\
$\mathrm{C}$ & 3.131036 & 1.574232 & -0.366859 \\
$\mathrm{C}$ & 3.197254 & -0.637855 & 0.455308 \\
$\mathrm{C}$ & 4.506258 & 1.712573 & -0.033100 \\
$\mathrm{C}$ & 2.343178 & 2.613034 & -0.964006 \\
$\mathrm{C}$ & 4.535562 & -0.549863 & 0.797254 \\
$\mathrm{H}$ & 2.645077 & -1.555315 & 0.634357 \\
$\mathrm{C}$ & 5.199712 & 0.671211 & 0.538986 \\
$\mathrm{H}$ & 5.013378 & 2.649293 & -0.231932 \\
$\mathrm{C}$ & 2.845564 & 3.902259 & -1.291585 \\
$\mathrm{H}$ & 5.041254 & -1.396372 & 1.246137 \\
$\mathrm{H}$ & 6.249970 & 0.790070 & 0.789074 \\
$\mathrm{C}$ & 0.232435 & 3.271313 & -1.791717 \\
$\mathrm{C}$ & 2.029708 & 4.850934 & -1.863406 \\
$\mathrm{H}$ & 3.883068 & 4.139644 & -1.088167 \\
$\mathrm{C}$ & 0.676393 & 4.538528 & -2.127554 \\
$\mathrm{H}$ & -0.798645 & 2.985302 & -1.975496 \\
$\mathrm{H}$ & 2.426053 & 5.831970 & -2.108744 \\
$\mathrm{H}$ & -0.002415 & 5.253813 & -2.576314
\end{tabular}




$\begin{array}{lrrr}\mathrm{C} & -0.168519 & 0.960996 & 1.194851 \\ \mathrm{C} & -1.630893 & 0.415829 & -1.279370 \\ \mathrm{C} & 0.880857 & -0.395307 & -2.544228 \\ \mathrm{C} & -0.048024 & -1.670523 & -0.080232 \\ 0 & -2.730701 & 0.529019 & -1.629228 \\ 0 & 1.180089 & -0.773020 & -3.593998 \\ 0 & -0.233535 & -2.762368 & 0.263633 \\ 0 & -0.458985 & 1.345597 & 2.244588 \\ \mathrm{~N} & 1.011444 & 2.328388 & -1.232444 \\ \mathrm{~N} & 2.499501 & 0.366355 & -0.104526\end{array}$

${ }^{3} \operatorname{MLCT}_{\text {bpy }}(2)$ - W(CO)4(bpy)

$\begin{array}{rrrr}\text { W } & 0.327725 & 0.260658 & -0.674620 \\ \mathrm{C} & 3.137366 & 1.579449 & -0.366881 \\ \mathrm{C} & 3.207841 & -0.635915 & 0.457350 \\ \mathrm{C} & 4.512913 & 1.721027 & -0.033882 \\ \mathrm{C} & 2.349934 & 2.617667 & -0.963671 \\ \mathrm{C} & 4.544990 & -0.543252 & 0.797615 \\ \mathrm{H} & 2.652265 & -1.551377 & 0.634461 \\ \mathrm{C} & 5.207303 & 0.680495 & 0.538176 \\ \mathrm{H} & 5.019655 & 2.657994 & -0.232678 \\ \mathrm{C} & 2.855441 & 3.906493 & -1.289999 \\ \mathrm{H} & 5.054586 & -1.387425 & 1.246749 \\ \mathrm{H} & 6.257545 & 0.800870 & 0.787964 \\ \mathrm{C} & 0.237510 & 3.280585 & -1.794380 \\ \mathrm{C} & 2.040734 & 4.855777 & -1.862044 \\ \mathrm{H} & 3.892936 & 4.143604 & -1.086056 \\ \mathrm{C} & 0.685574 & 4.545590 & -2.128119 \\ \mathrm{H} & -0.792417 & 2.990631 & -1.976848 \\ \mathrm{H} & 2.438455 & 5.836514 & -2.106719 \\ \mathrm{H} & 0.010146 & 5.263908 & -2.577402 \\ \mathrm{C} & -0.171207 & 0.981381 & 1.233889 \\ \mathrm{C} & -1.603221 & 0.326072 & -1.239181 \\ \mathrm{C} & 0.898164 & -0.402585 & -2.583924 \\ \mathrm{C} & -0.125819 & -1.620309 & -0.119949 \\ \mathrm{O} & -2.719505 & 0.369838 & -1.568021 \\ \mathrm{O} & 1.185161 & -0.785068 & -3.630219 \\ \mathrm{O} & -0.382024 & -2.709441 & 0.203002 \\ \mathrm{O} & -0.470149 & 1.357439 & 2.279166 \\ \mathrm{~N} & 1.013855 & 2.332288 & -1.233474 \\ \mathrm{~N} & 2.504136 & 0.367327 & -0.103841\end{array}$

${ }^{3} \operatorname{MLCT}_{\text {bpy }}$ (3) - W(CO)4(bpy)

$\begin{array}{lrrr}\text { W } & 0.330057 & 0.226824 & -0.666377 \\ \text { C } & 3.159712 & 1.558422 & -0.362012 \\ \text { C } & 3.176288 & -0.618559 & 0.527360 \\ \text { C } & 4.519470 & 1.745234 & -0.074410 \\ \text { C } & 2.328467 & 2.614421 & -0.985349 \\ \text { C } & 4.566340 & -0.505320 & 0.828685 \\ \text { H } & 2.606476 & -1.505013 & 0.762753\end{array}$




$\begin{array}{rrrr}\mathrm{C} & 5.237467 & 0.644573 & 0.538681 \\ \mathrm{H} & 5.023335 & 2.677272 & -0.281158 \\ \mathrm{C} & 2.842595 & 3.874715 & -1.332468 \\ \mathrm{H} & 5.067500 & -1.350560 & 1.291760 \\ \mathrm{H} & 6.295076 & 0.748442 & 0.759506 \\ \mathrm{C} & 0.218977 & 3.259113 & -1.760723 \\ \mathrm{C} & 2.008062 & 4.833114 & -1.900964 \\ \mathrm{H} & 3.886386 & 4.095928 & -1.158578 \\ \mathrm{C} & 0.669056 & 4.529313 & -2.120918 \\ \mathrm{H} & -0.814839 & 2.971777 & -1.915800 \\ \mathrm{H} & 2.404733 & 5.808490 & -2.168302 \\ \mathrm{H} & -0.019319 & 5.243295 & -2.558951 \\ \mathrm{C} & -0.172947 & 0.856059 & 1.226755 \\ \mathrm{C} & -1.596184 & 0.459942 & -1.290129 \\ \mathrm{C} & 0.916256 & -0.354450 & -2.551854 \\ \mathrm{C} & -0.108198 & -1.691484 & -0.120358 \\ 0 & -2.684832 & 0.632238 & -1.654688 \\ \mathrm{O} & 1.221794 & -0.685371 & -3.614870 \\ 0 & -0.353548 & -2.778002 & 0.195614 \\ \mathrm{O} & -0.485279 & 1.196804 & 2.284885 \\ \mathrm{~N} & 1.019461 & 2.331610 & -1.211569 \\ \mathrm{~N} & 2.507531 & 0.421404 & -0.080058\end{array}$

${ }^{3}$ MC- W(CO)4(bpy)

$\begin{array}{rrrr}\text { W } & 0.088466 & 0.079185 & -0.676220 \\ \mathrm{C} & 3.160991 & 1.570062 & -0.356401 \\ \mathrm{C} & 3.200621 & -0.602246 & 0.441232 \\ \mathrm{C} & 4.515489 & 1.734548 & -0.034140 \\ \mathrm{C} & 2.347253 & 2.642880 & -0.974165 \\ \mathrm{C} & 4.545403 & -0.514202 & 0.787984 \\ \mathrm{H} & 2.632657 & -1.510708 & 0.610339 \\ \mathrm{C} & 5.216419 & 0.682258 & 0.544209 \\ \mathrm{H} & 5.021051 & 2.672157 & -0.230484 \\ \mathrm{C} & 2.868678 & 3.905776 & -1.288527 \\ \mathrm{H} & 5.044518 & -1.366459 & 1.236949 \\ \mathrm{H} & 6.265893 & 0.797054 & 0.798620 \\ \mathrm{C} & 0.268227 & 3.263951 & -1.779484 \\ \mathrm{C} & 2.044343 & 4.864467 & -1.866856 \\ \mathrm{H} & 3.906179 & 4.142039 & -1.086011 \\ \mathrm{C} & 0.713456 & 4.537985 & -2.118556 \\ \mathrm{H} & -0.757984 & 2.959656 & -1.954889 \\ \mathrm{H} & 2.436135 & 5.846388 & -2.115115 \\ \mathrm{H} & 0.027377 & 5.248266 & -2.567799 \\ \mathrm{C} & -0.373880 & 0.798311 & 1.187990 \\ \mathrm{C} & -1.656146 & 0.766922 & -1.412677 \\ \mathrm{C} & 0.667372 & -0.551570 & -2.539903 \\ \mathrm{C} & 0.282186 & -1.788442 & 0.054013 \\ \mathrm{O} & -2.774644 & 0.882022 & -1.766897 \\ \mathrm{O} & 1.020475 & -0.887526 & -3.591823 \\ \mathrm{O} & 0.093425 & -2.898551 & 0.403008 \\ \mathrm{O} & -0.608456 & 1.224356 & 2.240393 \\ \mathrm{~N} & 1.057382 & 2.332970 & -1.221247\end{array}$




\section{${ }^{3}$ LC- W(CO)4(bpy)}

$\begin{array}{rrrr}\text { W } & 0.288534 & 0.231003 & -0.675022 \\ \mathrm{C} & 3.141622 & 1.602914 & -0.374177 \\ \mathrm{C} & 3.184817 & -0.598498 & 0.436315 \\ \mathrm{C} & 4.550231 & 1.751000 & -0.033539 \\ \mathrm{C} & 2.373540 & 2.615596 & -0.956299 \\ \mathrm{C} & 4.566839 & -0.502591 & 0.788672 \\ \mathrm{H} & 2.642892 & -1.520871 & 0.619008 \\ \mathrm{C} & 5.242016 & 0.706246 & 0.539251 \\ \mathrm{H} & 5.051671 & 2.689355 & -0.233553 \\ \mathrm{C} & 2.893849 & 3.934896 & -1.289317 \\ \mathrm{H} & 5.060636 & -1.356814 & 1.236915 \\ \mathrm{H} & 6.291660 & 0.816135 & 0.793404 \\ \mathrm{C} & 0.267462 & 3.247895 & -1.774574 \\ \mathrm{C} & 2.074362 & 4.882656 & -1.862347 \\ \mathrm{H} & 3.931026 & 4.166912 & -1.083430 \\ \mathrm{C} & 0.730401 & 4.555575 & -2.119521 \\ \mathrm{H} & -0.765187 & 2.972527 & -1.963378 \\ \mathrm{H} & 2.461588 & 5.865893 & -2.110789 \\ \mathrm{H} & 0.041093 & 5.261204 & -2.568294 \\ \mathrm{C} & -0.305318 & 0.858199 & 1.198920 \\ \mathrm{C} & -1.603336 & 0.430735 & -1.276566 \\ \mathrm{C} & 0.743715 & -0.501521 & -2.549610 \\ \mathrm{C} & -0.027153 & -1.647801 & -0.082254 \\ \mathrm{O} & -2.698079 & 0.609114 & -1.647850 \\ \mathrm{O} & 0.951493 & -0.948057 & -3.600173 \\ \mathrm{O} & -0.149493 & -2.751834 & 0.284180 \\ \mathrm{O} & -0.685536 & 1.173747 & 2.248737 \\ \mathrm{~N} & 1.023338 & 2.315974 & -1.225219 \\ \mathrm{~N} & 2.491209 & 0.380644 & -0.113029\end{array}$

\section{${ }^{3}$ MLCT $_{\text {CO }}-$ W(CO)4(bpy)}

$\begin{array}{rrrr}\text { W } & 0.278618 & 0.223437 & -0.675049 \\ \text { C } & 3.154765 & 1.564568 & -0.356579 \\ \text { C } & 3.198783 & -0.620212 & 0.448280 \\ \text { C } & 4.507967 & 1.724946 & -0.035753 \\ \text { C } & 2.340190 & 2.638603 & -0.974171 \\ \text { C } & 4.543003 & -0.526804 & 0.791074 \\ \text { H } & 2.632993 & -1.529000 & 0.619421 \\ \text { C } & 5.209752 & 0.671884 & 0.543013 \\ \text { H } & 5.014864 & 2.661546 & -0.233429 \\ \text { C } & 2.857663 & 3.900956 & -1.288012 \\ \text { H } & 5.046135 & -1.376408 & 1.240258 \\ \text { H } & 6.259451 & 0.788429 & 0.794869 \\ \text { C } & 0.250120 & 3.267575 & -1.785879 \\ \text { C } & 2.032775 & 4.860784 & -1.866686 \\ \text { H } & 3.894792 & 4.138443 & -1.085028 \\ \text { C } & 0.700655 & 4.539382 & -2.121664 \\ \text { H } & -0.776008 & 2.965769 & -1.962731\end{array}$




$\begin{array}{rrrr}\mathrm{H} & 2.426511 & 5.842180 & -2.113083 \\ \mathrm{H} & 0.018212 & 5.252930 & -2.570955 \\ \mathrm{C} & -0.189289 & 0.973984 & 1.247629 \\ \mathrm{C} & -1.616771 & 0.407509 & -1.272131 \\ \mathrm{C} & 0.887019 & -0.419968 & -2.597230 \\ \mathrm{C} & -0.052742 & -1.654588 & -0.087085 \\ 0 & -2.717386 & 0.552198 & -1.633219 \\ 0 & 1.095707 & -0.872365 & -3.659310 \\ 0 & -0.208614 & -2.755431 & 0.268636 \\ 0 & -0.575106 & 1.291549 & 2.309000 \\ \mathrm{~N} & 1.041805 & 2.334721 & -1.226557 \\ \mathrm{~N} & 2.514031 & 0.393613 & -0.111163\end{array}$

${ }^{3} \operatorname{MLCT}_{\text {bpy }}(4)$ - W(CO)4(bpy)

$\begin{array}{rrrr}\text { W } & 0.312405 & 0.249066 & -0.675489 \\ \mathrm{C} & 3.156782 & 1.558993 & -0.355415 \\ \mathrm{C} & 3.214889 & -0.627351 & 0.458795 \\ \mathrm{C} & 4.527552 & 1.737657 & -0.036834 \\ \mathrm{C} & 2.336100 & 2.641043 & -0.977644 \\ \mathrm{C} & 4.582562 & -0.515765 & 0.801559 \\ \mathrm{H} & 2.661796 & -1.540477 & 0.636716 \\ \mathrm{C} & 5.249891 & 0.689642 & 0.548206 \\ \mathrm{H} & 5.017417 & 2.680345 & -0.243818 \\ \mathrm{C} & 2.876248 & 3.914815 & -1.290983 \\ \mathrm{H} & 5.087414 & -1.362456 & 1.252597 \\ \mathrm{H} & 6.298336 & 0.815816 & 0.795743 \\ \mathrm{C} & 0.246017 & 3.286898 & -1.790702 \\ \mathrm{C} & 2.060763 & 4.894210 & -1.872405 \\ \mathrm{H} & 3.915745 & 4.132875 & -1.082753 \\ \mathrm{C} & 0.720492 & 4.576029 & -2.127332 \\ \mathrm{H} & -0.781694 & 2.999486 & -1.971176 \\ \mathrm{H} & 2.463801 & 5.871268 & -2.116040 \\ \mathrm{H} & 0.040387 & 5.291691 & -2.575083 \\ \mathrm{C} & -0.334367 & 0.839138 & 1.207843 \\ \mathrm{C} & -1.577019 & 0.484937 & -1.290216 \\ \mathrm{C} & 0.720528 & -0.522970 & -2.559757 \\ \mathrm{C} & 0.032523 & -1.638122 & -0.072061 \\ \mathrm{O} & -2.663198 & 0.684756 & -1.666805 \\ \mathrm{O} & 0.874516 & -1.003697 & -3.600465 \\ \mathrm{O} & -0.066640 & -2.740124 & 0.298415 \\ \mathrm{O} & -0.762741 & 1.110573 & 2.247402 \\ \mathrm{~N} & 1.041069 & 2.339840 & -1.227161 \\ \mathrm{~N} & 2.518321 & 0.392113 & -0.108674\end{array}$

${ }^{3}$ MLCT $_{\text {bpy }}(1)$ - W(CO)4(bpy) -UDFT(optimized)

$\begin{array}{lrrr}\text { W } & 0.352717 & 0.280383 & -0.673465 \\ \text { C } & 3.137395 & 1.584996 & -0.371547 \\ \text { C } & 3.190568 & -0.639550 & 0.460733 \\ \text { C } & 4.516692 & 1.711316 & -0.039539 \\ \text { C } & 2.355562 & 2.615231 & -0.962770 \\ \text { C } & 4.522089 & -0.551998 & 0.795556\end{array}$




$\begin{array}{rrrr}\mathrm{H} & 2.628567 & -1.550418 & 0.641217 \\ \mathrm{C} & 5.201632 & 0.669275 & 0.532202 \\ \mathrm{H} & 5.028528 & 2.644880 & -0.243651 \\ \mathrm{C} & 2.849108 & 3.909110 & -1.295740 \\ \mathrm{H} & 5.026414 & -1.398979 & 1.246451 \\ \mathrm{H} & 6.253306 & 0.777218 & 0.780703 \\ \mathrm{C} & 0.225331 & 3.268757 & -1.786628 \\ \mathrm{C} & 2.028800 & 4.851406 & -1.862299 \\ \mathrm{H} & 3.887433 & 4.148577 & -1.096430 \\ \mathrm{C} & 0.667951 & 4.527995 & -2.119784 \\ \mathrm{H} & -0.804207 & 2.974627 & -1.964324 \\ \mathrm{H} & 2.416228 & 5.834930 & -2.111287 \\ \mathrm{H} & -0.013255 & 5.243488 & -2.565936 \\ \mathrm{C} & -0.164161 & 0.996837 & 1.245898 \\ \mathrm{C} & -1.588212 & 0.367314 & -1.254274 \\ \mathrm{C} & 0.924984 & -0.394666 & -2.591875 \\ \mathrm{C} & -0.082346 & -1.617905 & -0.108109 \\ \mathrm{O} & -2.700767 & 0.422948 & -1.589170 \\ \mathrm{O} & 1.210985 & -0.781312 & -3.634511 \\ \mathrm{O} & -0.326346 & -2.707476 & 0.217952 \\ \mathrm{O} & -0.471191 & 1.366640 & 2.288667 \\ \mathrm{~N} & 1.011711 & 2.313449 & -1.224444 \\ \mathrm{~N} & 2.484375 & 0.373160 & -0.107136\end{array}$

${ }^{3} \operatorname{MLCT}_{\text {bpy }}$ (2) - W(CO)4(bpy) -UDFT(optimized)

\begin{tabular}{rrrr} 
W & 0.340525 & \multicolumn{1}{c}{0.271887} & \multicolumn{1}{c}{-0.675219} \\
$\mathrm{C}$ & 3.130870 & 1.578899 & -0.369047 \\
$\mathrm{C}$ & 3.184994 & -0.649786 & 0.438476 \\
$\mathrm{C}$ & 4.507031 & 1.704215 & -0.029382 \\
$\mathrm{C}$ & 2.348874 & 2.610194 & -0.966087 \\
$\mathrm{C}$ & 4.516180 & -0.565748 & 0.779902 \\
$\mathrm{H}$ & 2.629334 & -1.567418 & 0.606847 \\
$\mathrm{C}$ & 5.193448 & 0.658296 & 0.535731 \\
$\mathrm{H}$ & 5.015903 & 2.642148 & -0.220798 \\
$\mathrm{C}$ & 2.841047 & 3.901486 & -1.305419 \\
$\mathrm{H}$ & 5.018596 & -1.419315 & 1.220299 \\
$\mathrm{H}$ & 6.243319 & 0.766895 & 0.791034 \\
$\mathrm{C}$ & 0.214789 & 3.267855 & -1.763214 \\
$\mathrm{C}$ & 2.017719 & 4.847154 & -1.864246 \\
$\mathrm{H}$ & 3.882750 & 4.136456 & -1.118427 \\
$\mathrm{C}$ & 0.654598 & 4.527668 & -2.102289 \\
$\mathrm{H}$ & -0.820042 & 2.982549 & -1.927204 \\
$\mathrm{H}$ & 2.405584 & 5.828950 & -2.118863 \\
$\mathrm{H}$ & -0.033276 & 5.244104 & -2.536453 \\
$\mathrm{C}$ & -0.194959 & 1.039279 & 1.175621 \\
$\mathrm{C}$ & -1.627894 & 0.450004 & -1.256062 \\
$\mathrm{C}$ & 0.956960 & -0.432711 & -2.525995 \\
$\mathrm{C}$ & -0.008297 & -1.677571 & -0.108186 \\
$\mathrm{O}$ & -2.734727 & 0.569600 & -1.575656 \\
$\mathrm{O}$ & 1.294682 & -0.844672 & -3.548268 \\
$\mathrm{O}$ & -0.184329 & -2.778952 & 0.204013 \\
$\mathrm{O}$ & -0.514140 & 1.466435 & 2.197664
\end{tabular}




$\begin{array}{llll}\mathrm{N} & 1.008946 & 2.311980 & -1.218727 \\ \mathrm{~N} & 2.481408 & 0.370348 & -0.113586\end{array}$

${ }^{3}$ MC- W(CO)4(bpy) -UDFT(optimized)

$\begin{array}{rrrr}\text { W } & 0.166050 & 0.137619 & -0.677284 \\ \mathrm{C} & 3.163447 & 1.571833 & -0.359484 \\ \mathrm{C} & 3.194455 & -0.604591 & 0.442107 \\ \mathrm{C} & 4.519318 & 1.728194 & -0.040073 \\ \mathrm{C} & 2.350201 & 2.643902 & -0.973615 \\ \mathrm{C} & 4.539032 & -0.520799 & 0.785667 \\ \mathrm{H} & 2.621454 & -1.510110 & 0.613617 \\ \mathrm{C} & 5.215721 & 0.673174 & 0.538103 \\ \mathrm{H} & 5.028734 & 2.663155 & -0.239850 \\ \mathrm{C} & 2.864315 & 3.910090 & -1.285645 \\ \mathrm{H} & 5.035637 & -1.374150 & 1.235377 \\ \mathrm{H} & 6.266269 & 0.782764 & 0.790040 \\ \mathrm{C} & 0.263223 & 3.260170 & -1.776487 \\ \mathrm{C} & 2.035186 & 4.866618 & -1.860012 \\ \mathrm{H} & 3.901137 & 4.149640 & -1.082682 \\ \mathrm{C} & 0.704104 & 4.535379 & -2.111584 \\ \mathrm{H} & -0.762462 & 2.951976 & -1.951576 \\ \mathrm{H} & 2.422191 & 5.851018 & -2.105588 \\ \mathrm{H} & 0.015170 & 5.244741 & -2.557952 \\ \mathrm{C} & -0.308418 & 0.862668 & 1.186539 \\ \mathrm{C} & -1.659706 & 0.639940 & -1.379641 \\ \mathrm{C} & 0.745885 & -0.508875 & -2.540580 \\ \mathrm{C} & 0.159313 & -1.758916 & 0.017078 \\ \mathrm{O} & -2.776123 & 0.733765 & -1.730907 \\ \mathrm{O} & 1.095538 & -0.857040 & -3.591689 \\ \mathrm{O} & -0.048650 & -2.861598 & 0.362629 \\ \mathrm{O} & -0.553695 & 1.289355 & 2.238270 \\ \mathrm{~N} & 1.058182 & 2.329894 & -1.220776 \\ \mathrm{~N} & 2.514391 & 0.410416 & -0.117540\end{array}$

${ }^{1}$ GS - Mo(CO)4(bpy)

$\begin{array}{rrrr}\text { Mo } & 0.317079 & 0.252778 & -0.676201 \\ \mathrm{C} & 3.162093 & 1.572003 & -0.359006 \\ \mathrm{C} & 3.201957 & -0.611473 & 0.448557 \\ \mathrm{C} & 4.517923 & 1.727862 & -0.039950 \\ \mathrm{C} & 2.349847 & 2.643220 & -0.973635 \\ \mathrm{C} & 4.545829 & -0.520363 & 0.788652 \\ \mathrm{H} & 2.637885 & -1.520357 & 0.623619 \\ \mathrm{C} & 5.218710 & 0.676181 & 0.538395 \\ \mathrm{H} & 5.024958 & 2.663731 & -0.241445 \\ \mathrm{C} & 2.864590 & 3.908579 & -1.287138 \\ \mathrm{H} & 5.046230 & -1.371348 & 1.238396 \\ \mathrm{H} & 6.269139 & 0.789222 & 0.788438 \\ \mathrm{C} & 0.258646 & 3.270955 & -1.782024 \\ \mathrm{C} & 2.040521 & 4.868473 & -1.862561 \\ \mathrm{H} & 3.902060 & 4.144706 & -1.083536\end{array}$




$\begin{array}{rrrr}\mathrm{C} & 0.707507 & 4.542634 & -2.115623 \\ \mathrm{H} & -0.768132 & 2.972812 & -1.959988 \\ \mathrm{H} & 2.431765 & 5.851016 & -2.107979 \\ \mathrm{H} & 0.022467 & 5.255098 & -2.562794 \\ \mathrm{C} & -0.281329 & 0.879293 & 1.188514 \\ \mathrm{C} & -1.565597 & 0.446567 & -1.277238 \\ \mathrm{C} & 0.771397 & -0.482515 & -2.541676 \\ \mathrm{C} & 0.002391 & -1.615834 & -0.083167 \\ \mathrm{O} & -2.660053 & 0.614354 & -1.646110 \\ 0 & 0.979401 & -0.931524 & -3.588808 \\ 0 & -0.126035 & -2.716597 & 0.282831 \\ 0 & -0.664408 & 1.195582 & 2.234716 \\ \mathrm{~N} & 1.049639 & 2.332736 & -1.223780 \\ \mathrm{~N} & 2.513412 & 0.402440 & -0.112999\end{array}$

${ }^{3} \mathrm{MLCT}_{\text {bpy }}$ (1) - Mo(CO)4(bpy)

$\begin{array}{rrrr}\text { Mo } & 0.310889 & 0.248310 & -0.674702 \\ \mathrm{C} & 3.125837 & 1.570362 & -0.367096 \\ \mathrm{C} & 3.199148 & -0.639721 & 0.456476 \\ \mathrm{C} & 4.502408 & 1.711577 & -0.034338 \\ \mathrm{C} & 2.338113 & 2.608990 & -0.963992 \\ \mathrm{C} & 4.538385 & -0.550539 & 0.797966 \\ \mathrm{H} & 2.649545 & -1.558820 & 0.637049 \\ \mathrm{C} & 5.198679 & 0.672393 & 0.537673 \\ \mathrm{H} & 5.008148 & 2.648916 & -0.233982 \\ \mathrm{C} & 2.843757 & 3.898587 & -1.290966 \\ \mathrm{H} & 5.046360 & -1.395643 & 1.246957 \\ \mathrm{H} & 6.249029 & 0.794451 & 0.786368 \\ \mathrm{C} & 0.231060 & 3.273796 & -1.792518 \\ \mathrm{C} & 2.030738 & 4.849442 & -1.862592 \\ \mathrm{H} & 3.881598 & 4.134318 & -1.087130 \\ \mathrm{C} & 0.676523 & 4.541457 & -2.128232 \\ \mathrm{H} & -0.801019 & 2.990873 & -1.977427 \\ \mathrm{H} & 2.430284 & 5.829589 & -2.106840 \\ \mathrm{H} & -0.000348 & 5.258620 & -2.576958 \\ \mathrm{C} & -0.158902 & 0.964852 & 1.189315 \\ \mathrm{C} & -1.633850 & 0.404165 & -1.275869 \\ \mathrm{C} & 0.887353 & -0.386817 & -2.538355 \\ \mathrm{C} & -0.060155 & -1.670216 & -0.083656 \\ \mathrm{O} & -2.733944 & 0.502673 & -1.619366 \\ \mathrm{O} & 1.200129 & -0.752470 & -3.585590 \\ \mathrm{O} & -0.260098 & -2.758178 & 0.254363 \\ \mathrm{O} & -0.434416 & 1.359145 & 2.236633 \\ \mathrm{~N} & 1.005766 & 2.329408 & -1.234101 \\ \mathrm{~N} & 2.498877 & 0.360708 & -0.102629\end{array}$

${ }^{3} \operatorname{MLCT}_{\text {bpy }}$ (2) - Mo(CO)4(bpy)

$\begin{array}{rrrr}\text { Mo } & 0.324583 & 0.258352 & -0.674510 \\ \text { C } & 3.127601 & 1.571893 & -0.367027 \\ \text { C } & 3.207968 & -0.641314 & 0.459075\end{array}$




$\begin{array}{rrrr}\mathrm{C} & 4.504638 & 1.717551 & -0.035321 \\ \mathrm{C} & 2.340084 & 2.610216 & -0.963672 \\ \mathrm{C} & 4.546031 & -0.546135 & 0.798454 \\ \mathrm{H} & 2.656286 & -1.559128 & 0.638221 \\ \mathrm{C} & 5.203086 & 0.680096 & 0.536579 \\ \mathrm{H} & 5.009163 & 2.655489 & -0.235125 \\ \mathrm{C} & 2.849944 & 3.899325 & -1.288870 \\ \mathrm{H} & 5.058924 & -1.388289 & 1.247662 \\ \mathrm{H} & 6.253353 & 0.804792 & 0.784636 \\ \mathrm{C} & 0.232356 & 3.282102 & -1.796156 \\ \mathrm{C} & 2.039291 & 4.851669 & -1.860781 \\ \mathrm{H} & 3.887803 & 4.134019 & -1.084029 \\ \mathrm{C} & 0.683117 & 4.547247 & -2.129165 \\ \mathrm{H} & -0.798809 & 2.996555 & -1.980550 \\ \mathrm{H} & 2.441202 & 5.831224 & -2.103846 \\ \mathrm{H} & 0.010522 & 5.268182 & -2.578544 \\ \mathrm{C} & -0.157182 & 0.991373 & 1.233521 \\ \mathrm{C} & -1.600350 & 0.320639 & -1.236292 \\ \mathrm{C} & 0.911407 & -0.391810 & -2.583128 \\ \mathrm{C} & -0.130630 & -1.615940 & -0.122584 \\ \mathrm{O} & -2.715956 & 0.349184 & -1.558552 \\ \mathrm{O} & 1.218188 & -0.757961 & -3.626961 \\ \mathrm{O} & -0.401601 & -2.700125 & 0.194217 \\ \mathrm{O} & -0.435084 & 1.382108 & 2.276529 \\ \mathrm{~N} & 1.003224 & 2.331691 & -1.236063 \\ \mathrm{~N} & 2.500733 & 0.357225 & -0.101258\end{array}$

${ }^{3} \mathrm{MLCT}_{\text {bpy }}$ (3) - Mo(CO)4(bpy)

$\begin{array}{rrrr}\text { Mo } & 0.295423 & 0.266315 & -0.685311 \\ \mathrm{C} & 3.127800 & 1.551664 & -0.358793 \\ \mathrm{C} & 3.177596 & -0.640639 & 0.448748 \\ \mathrm{C} & 4.486756 & 1.703827 & -0.032944 \\ \mathrm{C} & 2.332129 & 2.638988 & -0.975971 \\ \mathrm{C} & 4.526921 & -0.552143 & 0.794753 \\ \mathrm{H} & 2.619700 & -1.553915 & 0.623023 \\ \mathrm{C} & 5.184883 & 0.646449 & 0.545360 \\ \mathrm{H} & 4.986411 & 2.641353 & -0.232218 \\ \mathrm{C} & 2.886557 & 3.893086 & -1.274154 \\ \mathrm{H} & 5.028511 & -1.402555 & 1.243009 \\ \mathrm{H} & 6.235227 & 0.763167 & 0.797432 \\ \mathrm{C} & 0.224163 & 3.271970 & -1.799779 \\ \mathrm{C} & 2.021218 & 4.887262 & -1.877435 \\ \mathrm{H} & 3.920577 & 4.123919 & -1.067451 \\ \mathrm{C} & 0.719639 & 4.567657 & -2.128720 \\ \mathrm{H} & -0.800011 & 2.984420 & -1.985666 \\ \mathrm{H} & 2.415736 & 5.868616 & -2.121104 \\ \mathrm{H} & 0.039489 & 5.284771 & -2.579898 \\ \mathrm{C} & -0.180177 & 0.988631 & 1.175072 \\ \mathrm{C} & -1.662570 & 0.340197 & -1.260005 \\ \mathrm{C} & 0.857271 & -0.364559 & -2.554820 \\ \mathrm{C} & -0.008708 & -1.651665 & -0.073400 \\ \mathrm{O} & -2.770643 & 0.375452 & -1.583452 \\ \mathrm{O} & 1.163159 & -0.734653 & -3.601968\end{array}$




$\begin{array}{rrrr}0 & -0.153136 & -2.743680 & 0.283245 \\ 0 & -0.456469 & 1.378682 & 2.223195 \\ \mathrm{~N} & 1.052003 & 2.332512 & -1.225597 \\ \mathrm{~N} & 2.500439 & 0.375099 & -0.108691\end{array}$

${ }^{3} \operatorname{MLCT}_{\text {bpy }}(4)$ - Mo(CO)4(bpy)

$\begin{array}{rrrr}\text { Mo } & 0.328461 & 0.288344 & -0.681235 \\ \mathrm{C} & 3.150176 & 1.561833 & -0.361249 \\ \mathrm{C} & 3.222376 & -0.619920 & 0.470309 \\ \mathrm{C} & 4.517092 & 1.720134 & -0.065631 \\ \mathrm{C} & 2.338440 & 2.639452 & -0.966878 \\ \mathrm{C} & 4.575488 & -0.524156 & 0.793011 \\ \mathrm{H} & 2.665952 & -1.531208 & 0.662026 \\ \mathrm{C} & 5.227614 & 0.675034 & 0.512069 \\ \mathrm{H} & 5.014063 & 2.653113 & -0.294431 \\ \mathrm{C} & 2.867569 & 3.907668 & -1.252341 \\ \mathrm{H} & 5.088097 & -1.365956 & 1.245010 \\ \mathrm{H} & 6.282887 & 0.796804 & 0.740283 \\ \mathrm{C} & 0.215283 & 3.258609 & -1.793280 \\ \mathrm{C} & 1.989888 & 4.894138 & -1.868542 \\ \mathrm{H} & 3.889954 & 4.164368 & -1.019464 \\ \mathrm{C} & 0.695855 & 4.564897 & -2.128123 \\ \mathrm{H} & -0.801140 & 2.952989 & -1.986041 \\ \mathrm{H} & 2.380135 & 5.877112 & -2.114611 \\ \mathrm{H} & 0.010005 & 5.270456 & -2.587891 \\ \mathrm{C} & -0.231257 & 0.887651 & 1.246504 \\ \mathrm{C} & -1.548557 & 0.497600 & -1.302308 \\ \mathrm{C} & 0.863505 & -0.513393 & -2.540799 \\ \mathrm{C} & -0.112963 & -1.609533 & -0.106307 \\ \mathrm{O} & -2.639691 & 0.641540 & -1.671790 \\ \mathrm{O} & 1.117052 & -1.006328 & -3.547375 \\ \mathrm{O} & -0.347049 & -2.695548 & 0.226885 \\ \mathrm{O} & -0.575032 & 1.156530 & 2.309537 \\ \mathrm{~N} & 1.055359 & 2.314991 & -1.223526 \\ \mathrm{~N} & 2.530332 & 0.383007 & -0.087352\end{array}$

${ }^{3} \mathrm{MC}-\mathrm{Mo}(\mathrm{CO}) 4(\mathrm{bpy})$

$\begin{array}{rrrr}\text { Mo } & 0.068605 & 0.064140 & -0.675934 \\ \text { C } & 3.169905 & 1.570722 & -0.363069 \\ \text { C } & 3.211395 & -0.590480 & 0.459523 \\ \text { C } & 4.535286 & 1.725071 & -0.082289 \\ \text { C } & 2.350262 & 2.651281 & -0.967649 \\ \text { C } & 4.565052 & -0.511220 & 0.776237 \\ \text { H } & 2.641303 & -1.493546 & 0.652291 \\ \text { C } & 5.240532 & 0.673919 & 0.494075 \\ \text { H } & 5.048022 & 2.650893 & -0.313347 \\ \text { C } & 2.865249 & 3.926489 & -1.242574 \\ \text { H } & 5.067411 & -1.360377 & 1.227676 \\ \text { H } & 6.298172 & 0.781124 & 0.716369 \\ \text { C } & 0.281768 & 3.272214 & -1.795243 \\ \text { C } & 2.043043 & 4.889183 & -1.818486\end{array}$




$\begin{array}{rrrr}\mathrm{H} & 3.893726 & 4.172038 & -1.007265 \\ \mathrm{C} & 0.721295 & 4.556411 & -2.106030 \\ \mathrm{H} & -0.740215 & 2.965185 & -1.992602 \\ \mathrm{H} & 2.430051 & 5.880302 & -2.036236 \\ \mathrm{H} & 0.038935 & 5.269204 & -2.557185 \\ \mathrm{C} & -0.422106 & 0.805850 & 1.166630 \\ \mathrm{C} & -1.670186 & 0.734510 & -1.445922 \\ \mathrm{C} & 0.662966 & -0.598554 & -2.518097 \\ \mathrm{C} & 0.247917 & -1.793578 & 0.087194 \\ \mathrm{O} & -2.777497 & 0.842996 & -1.815725 \\ \mathrm{O} & 1.024853 & -0.953310 & -3.558912 \\ \mathrm{O} & 0.055770 & -2.891345 & 0.451467 \\ \mathrm{O} & -0.673539 & 1.244842 & 2.207865 \\ \mathrm{~N} & 1.067146 & 2.339074 & -1.239881 \\ \mathrm{~N} & 2.524772 & 0.417195 & -0.096419\end{array}$

\section{${ }^{3} \mathrm{LC}-\mathrm{Mo}(\mathrm{CO}) 4(\mathrm{bpy})$}

$\begin{array}{rrrr}\text { Mo } & 0.281567 & 0.225807 & -0.674917 \\ \mathrm{C} & 3.137053 & 1.598927 & -0.374331 \\ \mathrm{C} & 3.189559 & -0.599415 & 0.438245 \\ \mathrm{C} & 4.547186 & 1.751969 & -0.035700 \\ \mathrm{C} & 2.368588 & 2.612135 & -0.956529 \\ \mathrm{C} & 4.572748 & -0.500774 & 0.789535 \\ \mathrm{H} & 2.651144 & -1.523858 & 0.623092 \\ \mathrm{C} & 5.242759 & 0.710906 & 0.536908 \\ \mathrm{H} & 5.046686 & 2.691046 & -0.237153 \\ \mathrm{C} & 2.894304 & 3.931318 & -1.288152 \\ \mathrm{H} & 5.070561 & -1.352508 & 1.238128 \\ \mathrm{H} & 6.292543 & 0.824907 & 0.789104 \\ \mathrm{C} & 0.267668 & 3.253105 & -1.775667 \\ \mathrm{C} & 2.079295 & 4.881958 & -1.860475 \\ \mathrm{H} & 3.931913 & 4.160893 & -1.081725 \\ \mathrm{C} & 0.733685 & 4.561055 & -2.119806 \\ \mathrm{H} & -0.766197 & 2.981943 & -1.966075 \\ \mathrm{H} & 2.470681 & 5.864044 & -2.107394 \\ \mathrm{H} & 0.047750 & 5.270090 & -2.568434 \\ \mathrm{C} & -0.302239 & 0.857430 & 1.193316 \\ \mathrm{C} & -1.600800 & 0.414362 & -1.270033 \\ \mathrm{C} & 0.744006 & -0.497851 & -2.543804 \\ \mathrm{C} & -0.042017 & -1.640939 & -0.088744 \\ \mathrm{O} & -2.697688 & 0.576674 & -1.635683 \\ \mathrm{O} & 0.955938 & -0.940443 & -3.593136 \\ \mathrm{O} & -0.180147 & -2.742764 & 0.271961 \\ \mathrm{O} & -0.677858 & 1.175881 & 2.241842 \\ \mathrm{~N} & 1.017793 & 2.319956 & -1.227868 \\ \mathrm{~N} & 2.493410 & 0.374376 & -0.110044\end{array}$

${ }^{3} \mathrm{MLCT}_{\mathrm{CO}}{ }^{3} \mathrm{MC}-\mathrm{Mo}(\mathrm{CO}) 4(\mathrm{bpy})$

$\begin{array}{rrrr}\text { Mo } & 0.166878 & 0.138692 & -0.675689 \\ \text { C } & 3.192934 & 1.590043 & -0.353190 \\ \text { C } & 3.235765 & -0.584636 & 0.452224 \\ \text { C } & 4.546434 & 1.756794 & -0.031962 \\ \text { C } & 2.375298 & 2.668597 & -0.977138\end{array}$




$\begin{array}{rrrr}\mathrm{C} & 4.582018 & -0.494259 & 0.799157 \\ \mathrm{H} & 2.664293 & -1.491940 & 0.621809 \\ \mathrm{C} & 5.247277 & 0.703689 & 0.549984 \\ \mathrm{H} & 5.054628 & 2.692911 & -0.229588 \\ \mathrm{C} & 2.899527 & 3.929204 & -1.291850 \\ \mathrm{H} & 5.085576 & -1.342597 & 1.250726 \\ \mathrm{H} & 6.296846 & 0.821474 & 0.803325 \\ \mathrm{C} & 0.294588 & 3.294830 & -1.788503 \\ \mathrm{C} & 2.074682 & 4.888415 & -1.873589 \\ \mathrm{H} & 3.936717 & 4.167609 & -1.089290 \\ \mathrm{C} & 0.743327 & 4.569049 & -2.129001 \\ \mathrm{H} & -0.731890 & 2.987643 & -1.963249 \\ \mathrm{H} & 2.470079 & 5.869048 & -2.121927 \\ \mathrm{H} & 0.062478 & 5.282973 & -2.580575 \\ \mathrm{C} & -0.399563 & 0.803193 & 1.227565 \\ \mathrm{C} & -1.672068 & 0.487709 & -1.316808 \\ \mathrm{C} & 0.665928 & -0.576945 & -2.579278 \\ \mathrm{C} & 0.009143 & -1.729382 & -0.043084 \\ \mathrm{O} & -2.770958 & 0.646701 & -1.682191 \\ \mathrm{O} & 0.944482 & -0.972922 & -3.634917 \\ \mathrm{O} & -0.132841 & -2.832329 & 0.317018 \\ \mathrm{O} & -0.712027 & 1.173256 & 2.283116 \\ \mathrm{~N} & 1.083796 & 2.368055 & -1.228855 \\ \mathrm{~N} & 2.556546 & 0.425353 & -0.107779\end{array}$

$\begin{array}{rrrr}{ }^{3} \mathbf{M L C T}_{\text {bpy }} \text { (1) - Mo(CO)4(bpy) -UDFT(optimized) } \\ \text { Mo } & 0.343586 & 0.272405 & -0.673777 \\ \mathrm{C} & 3.125699 & 1.573792 & -0.372417 \\ \mathrm{C} & 3.171111 & -0.632564 & 0.493767 \\ \mathrm{C} & 4.505747 & 1.698731 & -0.043905 \\ \mathrm{C} & 2.341203 & 2.607484 & -0.962327 \\ \mathrm{C} & 4.505136 & -0.549123 & 0.827874 \\ \mathrm{H} & 2.607219 & -1.538698 & 0.695718 \\ \mathrm{C} & 5.189090 & 0.662329 & 0.542025 \\ \mathrm{H} & 5.020814 & 2.627136 & -0.263362 \\ \mathrm{C} & 2.833653 & 3.902469 & -1.291814 \\ \mathrm{H} & 5.002870 & -1.390602 & 1.296082 \\ \mathrm{H} & 6.241703 & 0.770557 & 0.786525 \\ \mathrm{C} & 0.225958 & 3.248991 & -1.818682 \\ \mathrm{C} & 2.018162 & 4.841766 & -1.872346 \\ \mathrm{H} & 3.867978 & 4.146395 & -1.077197 \\ \mathrm{C} & 0.665363 & 4.511649 & -2.151731 \\ \mathrm{H} & -0.799912 & 2.952139 & -2.016899 \\ \mathrm{H} & 2.406111 & 5.826127 & -2.117316 \\ \mathrm{H} & -0.012610 & 5.219492 & -2.614712 \\ \mathrm{C} & -0.052797 & 0.901704 & 1.263474 \\ \mathrm{C} & -1.600129 & 0.375713 & -1.340568 \\ \mathrm{C} & 0.863849 & -0.262408 & -2.610150 \\ \mathrm{C} & -0.074496 & -1.633964 & -0.022686 \\ \mathrm{O} & -2.682883 & 0.434079 & -1.740332 \\ \mathrm{O} & 1.135700 & -0.533801 & -3.694112\end{array}$




$\begin{array}{rrrr}0 & -0.306954 & -2.696314 & 0.368437 \\ 0 & -0.253038 & 1.227790 & 2.347987 \\ \mathrm{~N} & 1.005253 & 2.307749 & -1.233960 \\ \mathrm{~N} & 2.476505 & 0.369210 & -0.097135\end{array}$

${ }^{3}$ MLCT $_{\text {bpy }}$ (2) - Mo(CO)4(bpy) -UDFT(optimized)

$\begin{array}{rrrr}\text { Mo } & 0.476250 & 0.348871 & -0.663857 \\ \mathrm{C} & 3.252236 & 1.646631 & -0.361007 \\ \mathrm{C} & 3.312531 & -0.575682 & 0.472982 \\ \mathrm{C} & 4.632591 & 1.776373 & -0.029816 \\ \mathrm{C} & 2.470311 & 2.677303 & -0.952846 \\ \mathrm{C} & 4.645154 & -0.486460 & 0.807534 \\ \mathrm{H} & 2.753000 & -1.488157 & 0.654923 \\ \mathrm{C} & 5.320562 & 0.736554 & 0.542224 \\ \mathrm{H} & 5.142742 & 2.710696 & -0.234754 \\ \mathrm{C} & 2.967694 & 3.971226 & -1.284911 \\ \mathrm{H} & 5.151891 & -1.331905 & 1.258703 \\ \mathrm{H} & 6.372259 & 0.847852 & 0.789606 \\ \mathrm{C} & 0.344303 & 3.337533 & -1.778364 \\ \mathrm{C} & 2.150513 & 4.915987 & -1.851798 \\ \mathrm{H} & 4.006300 & 4.208743 & -1.084649 \\ \mathrm{C} & 0.789065 & 4.597310 & -2.111277 \\ \mathrm{H} & -0.686185 & 3.046384 & -1.957427 \\ \mathrm{H} & 2.541352 & 5.898577 & -2.099601 \\ \mathrm{H} & 0.110113 & 5.314853 & -2.557672 \\ \mathrm{C} & -0.011327 & 1.089160 & 1.255901 \\ \mathrm{C} & -1.461680 & 0.427115 & -1.242165 \\ \mathrm{C} & 1.079690 & -0.302532 & -2.582764 \\ \mathrm{C} & 0.033919 & -1.544802 & -0.103078 \\ \mathrm{O} & -2.573884 & 0.462541 & -1.570929 \\ \mathrm{O} & 1.400970 & -0.660180 & -3.622931 \\ \mathrm{O} & -0.229396 & -2.629021 & 0.215469 \\ \mathrm{O} & -0.281999 & 1.485838 & 2.296337 \\ \mathrm{~N} & 1.126304 & 2.381572 & -1.216989 \\ \mathrm{~N} & 2.604647 & 0.433104 & -0.094123 \\ & & & \end{array}$


